Prognost i c val ue of Tc- 99m M Bl perfor med during middl e course of preoper at i ve chemot her apy in pat i ent s wi th mal i gnant bone and sof $t$-tissue turrors

\begin{tabular}{|l|l|}
\hline 著者 & $\begin{array}{l}\text { Wakabayashi H roshi, Taki Juni chi, I naki Anr i, } \\
\text { Sumi ya Hi sashi, Zen Yoh, Tsuchi ya Hi royuki , } \\
\text { Ki nuya Sei go }\end{array}$ \\
\hline $\begin{array}{l}\text { j our nal or } \\
\text { publ i cat i on ti tl e }\end{array}$ & Cl i ni cal Nucl ear Nedi ci ne \\
\hline vol une & 37 \\
\hline number & 1 \\
\hline page r ange & $1-8$ \\
\hline year & $2012-01-01$ \\
\hline URL & ht t p: //hdl . handl e. net /2297/30311 \\
\hline
\end{tabular}




\section{Prognostic Value of Tc-99m-MIBI Performed during Middle Course of the Preoperative Chemotherapy in Patients with Malignant Bone and Soft Tissue Tumors}

Hiroshi Wakabayashi, ${ }^{1}$ Junichi Taki, ${ }^{2}$ Anri Inaki, ${ }^{1}$ Hisashi Sumiya, ${ }^{2}$

Yoh Zen, ${ }^{3}$ Hiroyuki Tsuchiya, ${ }^{4}$ Seigo Kinuya ${ }^{1}$

${ }^{1}$ Department of Biotracer medicine, Kanazawa University Graduate School of Medical Sciences,

Kanazawa, Japan

${ }^{2}$ Department of Nuclear medicine, Kanazawa University Hospital, Kanazawa, Japan

${ }^{3}$ Pathology Section, Kanazawa University Hospital, Kanazawa, Japan

${ }^{4}$ Department of Orthopedic Surgery, Kanazawa University Hospital, Kanazawa, Japan

Address for correspondence and reprint requests:

Junichi Taki, MD, PhD

Department of nuclear medicine, Kanazawa University Hospital

13-1 Takara-machi, Kanazawa, 920-8641, Japan

Tel: +81-76-265-2333

Fax: +81-76-234-4257

E-mail: taki@med.kanazawa-u.ac.jp 


\section{ABSTRACT}

Purpose: This study was aimed to determine whether Tc-99m-hexakis-2-methoxyisobutylisonitrile (MIBI) scintigraphy performed in the middle of preoperative chemotherapy have a prognostic value in patients with malignant bone and soft tissue tumors (MBST).

Materials and Methods: In 90 patients with MBST, Tc-99m-MIBI scintigraphy was performed at 15 min after tracer injection before the first and after the third chemotherapy cycles. After 5 cycles of chemotherapy and tumor resection, therapeutic effect was assessed by histopathology. The $\%$ reduction of uptake ratio $(\Delta \mathrm{UR})$ was calculated according to the following equation: $100 \times$ [(prechemotherapy UR - post middle course of chemotherapy UR)/ prechemotherapy UR].

Results: The average follow-up for the entire population was 52 months. 21 patients had clinically detectable metastases at initial presentation (primary metastasis). Kaplan-Meier analysis demonstrated that absence of metastasis was associated with good survival in all patients, patients with bone tumor and soft tissue tumor ( $\mathrm{P}<0.0001, \mathrm{P}<0.0001$, and $\mathrm{P}=0.0003$, respectively) and $\Delta \mathrm{UR}$ $\geqq 30 \%$ was also associated with survival in all patients and patients with bone tumor $(\mathrm{P}=0.011$ and $\mathrm{P}=0.047$, repectively) but was marginal in soft tissue tumor $(\mathrm{P}=0.091)$. Multivariate analysis showed that primary metastasis was the most powerful independent predictor of a lethal clinical outcome in all patients, in both bone and soft tissue tumors (Hazard Ratio 4.9, 95\% confidence interval (CI) 2.619.08, $\mathrm{P}<0.0001$; HR 15.1, CI 4.86-52.7, $\mathrm{P}<0.0001$; HR 3.7, CI 1.45-8.94, $\mathrm{P}=0.0069$, respectively), and showed that Tc-99m-MIBI scintigraphy had a good independent long-term prognostic value in all patients and bone tumor (Hazard Ratio 2.2, CI 1.14- 4.43, $\mathrm{P}=0.017$; HR 6.0, CI 2.01-21.6, $\mathrm{P}=0.0009$, respectively) but not in soft tissue tumor (HR 1.5, CI 0.61-4.09, $\mathrm{P}=0.38$ ). Good disease free survival was associated with $\Delta \mathrm{UR} \geqq 30 \%$ in all patients and patients with soft tissue tumor $(\mathrm{P}=0.0093$ and $\mathrm{P}=0.017$, respectively) but not in bone tumor $(\mathrm{P}=0.19)$.

Conclusion: Tc-99m-MIBI scintigraphy at the middle course of preoperative chemotherapy could be used as a prognostic indicator in patients with MBST.

Key words: Tc-99m-MIBI; malignant bone and soft tissue tumors; osteosarcoma; survival; chemotherapy 


\section{INTRODUCTION}

Preoperative chemotherapy is essential to improve the prognosis of the patients with malignant bone and soft tissue tumors (MBST). For the evaluation of tumor response to preoperative chemotherapy, several modalities have been used, including CT, $\underline{\text { dynamic }}$ MRI, angiography and radionuclide imaging. ${ }^{1-5}$ Although tumor size can be well evaluated with CT and MRI, estimating residual tumor cell viability is somewhat difficult. The assessment of residual tumor cell viability is important to develop treatment strategy of limb-sparing surgery. ${ }^{6-9}$ Early prediction of the tumor response to preoperative chemotherapy would be beneficial to treatment planning. The histopathological response to preoperative chemotherapy assessed after operation is known as a prognostic factor.

Tc-99m-hexakis-2-methoxyisobutylisonitrile (MIBI) has been used as a popular myocardial perfusion imaging agent in patients with coronary artery disease. Tc-99m-MIBI has also been recognized as a useful imaging agent for various tumors, including bone and soft tissue tumors. ${ }^{10}$ It is valuable not only to detect various tumors but also to evaluate the tumor response to chemotherapy including MBST. ${ }^{11,12}$

Several studies have shown the possibility that the change of the Tc-99m-MIBI uptake from pre- to post-chemotherapy reflects chemotherapeutic effect in patients with bone sarcomas. ${ }^{13,14}$

The change of Tc-99m-MIBI uptake from pre-chemotherapy to middle course of preoperative chemotherapy has been proved to reflect histopathological response to preoperative chemotherapy, ${ }^{11}$ 12 therefore, the change of Tc-99m-MIBI uptake might be a prognostic factor like tumor size, existence of primary metastasis at the diagnosis. ${ }^{15,16}$ However, no published study has assessed the value of Tc-99m-MIBI scintigraphy as an indicator of prognosis in patients with MBST. 
This study was aimed to determine whether the combination of Tc-99m-MIBI scintigraphy before and after the middle course of preoperative chemotherapy have a prognostic value or not.

\section{MATERIALS AND METHODS}

\section{Patients}

Following institutional ethical committee approval and informed patient consent, 90 patients (63 males and 27 females; average age, 31.0 years; range, 5-74 years) with various malignant bone and soft-tissue tumors (42 patients with bone tumors and 48 patients with soft tissue tumors), confirmed pathologically in specimens obtained by biopsy and/or resection after chemotherapy, and who were treated between May 1992 and December 2003 were recruited in this study. There were 32 osteosarcomas (including 1 extraosseous osteosarcoma); 15 malignant fibrous histiocytomas; 9 Ewing’s sarcomas; 7 rhabdomyosarcomas; 6 synovial sarcomas; 6 liposarcomas; 4 leiomyosarcomas; 2 clear cell sarcomas; 2 chondrosarcomas; 2 alveolar soft part sarcomas; 2 angiosarcomsa; 2 spindle cell sarcomas; 1 malignant schwannoma.

A total of 71 (79\%) primary tumors were located in extremities and $19(21 \%)$ occurred in truncal site.

Chemotherapy has done with caffeine-assisted chemotherapy. All patients received 5 cycles of preoperative intraarterial chemotherapy at intervals of 2-3 weeks. In each chemotherapy cycle, cisplatin $(120 \mathrm{mg} / \mathrm{m} 2)$ was continuously infused through intraarterial catheter for $1-2 \mathrm{~h}$ followed by 48-h continuous intraarterial infusion of doxorubicin $\left(60 \mathrm{mg} / \mathrm{m}_{2}\right)$ and 72 -h intraarterial infusion of caffeine. 8, 17

Patients underwent clinical evaluation and imaging studies, including radiography, CT, and MRI, for the assessment of primary tumor. They also underwent a chest CT and radionuclide wholebody bone scan to detect osseous metastases. Follow-up evaluation to detect local recurrence and metastasis consisted of radiography, CT, MRI, bone scan, and Tl-201 scan. 


\section{Tc-99m-MIBI Scintigraphy}

The Tc-99m-MIBI scintigraphy was performed before preoperative chemotherapy and after the 3 cycles of preoperative chemotherapy in all 90 patients. Planar imaging was performed at 15 min after intravenous infusion of $600-740 \mathrm{MBq}(16.2-20 \mathrm{mCi})$ of Tc-99m-MIBI with a gamma camera equipped with a low-energy, high-resolution, parallel-hole collimator.

\section{Image Analysis}

Tc-99m-MIBI scintigraphy was evaluated quantitatively. A region of interest (ROI) was set manually on the whole lesion and a symmetrical ROI was set on the contralateral normal area as a background. If it was difficult to delineate the lesion on the scintigraphic image, we referred to CT or MR image. The uptake ratio was then calculated by dividing the count density (average counts / pixel) of the lesion by that of the contralateral normal area.

In the analysis of the images obtained after the 3 cycles of preoperative chemotherapy, tumor ROI was newly set to cover the whole lesion as described above. Therefore, ROI size was changed depending on the size of the tumor. When the tumor uptake of the radionuclide disappeared completely, the same ROI delineated at prechemotherapy was applied to calculate the indices.

For the prediction of the chemotherapeutic effect, the percent reduction of uptake ratio $(\Delta U R)$ was calculated as follows:

$\Delta \mathrm{UR}(\%)=100$ (prechemotherapy UR - post middle course of chemotherapy UR) / (prechemotherapy UR)

Less than $30 \%$ and $30 \%$ or more $\Delta U R$ were defined as poor and good response to chemotherapy, respectively, based on the previous study which proved Tc-99m-MIBI imaging performed in the middle course of preoperative chemotherapy well predicted the final tumor histopathological response to chemotherapy in patients with MBST. ${ }^{11,12}$ 


\section{Histopathological Evaluation of Chemotherapeutic Effect}

The histopathological response to chemotherapy was determined based on the degree of necrosis in the largest slice of the resected tumor. Grade IV (100\% necrosis) was considered complete response (CR), and Grade III (90\% $\leq \sim<100 \%$ necrosis) was considered partial response (PR). Tumors showing

Grade II and I ( $50 \%<\sim<90 \%$ and $\leq 50 \%$ necrosis, respectively) were considered as no change. ${ }^{18}$

Less than $90 \%$ and $90 \%$ or more necrosis were judged as poor and good response to chemotherapy, respectively.

\section{Statistical Analysis}

Prognostic values were determined using a statistical software package (JMP® Statistical Discovery Software). Overall survival and disease free survival were analyzed by the Kaplan-Meier method to clarify the time-dependent cumulative survival rate, and the curves were compared using the 2-sample log-rank test. $\mathrm{P}<0.05$ was considered statically significant. Univariate and multivariate Cox proportional hazard regression analyses were used to identify predictors of overall survival and disease free survival. Overall survival was defined as the time from the initial diagnosis to death from any cause. Disease free survival was defined as the time from the surgical operation to either metastasis, local recurrence, or death from any cause.

We examined the following factors for prognostic significance; sex, age (more than 40 years or not), site of the tumor (extremity or truncal site), tumor type (bone tumor or soft tissue tumor), metastasis at initial presentation, $\Delta \mathrm{UR}$, histopathological response, surgical margin, Tc-99m-MIBI uptake ratios before chemotherapy and after chemotherapy.

\section{RESULTS}

Follow-up ranged from 4 to 142 months, with an average follow-up of 52 months. At initial 
presentation, 21 patients (23\%) had clinically detectable metastases (primary metastasis) and 69 patients (77\%) didn't have metastasis (absence of metastasis). Two patients with osteosarcoma refused surgical operation after preoperative chemotherapy. Therefore, they were excluded from analysis. All other 88 patients had limb-salvage surgery.

Final histopathological types of MBST were high-grade malignant tumor in all 88 patients (100\%). In histopathological evaluation of the tumor response to preoperative chemotherapy, 39 showed good response and 49 showed poor response. Good and poor responses of Tc-99m-MIBI uptake change ( $\Delta \mathrm{UR} \geqq 30 \%$ and $\Delta \mathrm{UR}<30 \%$, respectively) were concordant with histopathological response to chemotherapy in $88 \%$ of the patients (Table 1). This concordance was $90 \%$ (36 out of 40 patients) in bone tumors and $85 \%$ (41 out of 48 patients) in soft tissue tumors. Eighty patients showed negative surgical margins, 8 patients showed positive surgical margins. In all patients with positive surgical margins, postoperative histopathological examination of the resected tumors demonstrated no change and $\Delta \mathrm{UR}(\%)$ showed poor response $(<30 \%)$.

Kaplan-Meier analysis demonstrated that absence of metastasis was significantly associated with good overall survival in all patients, in both patients with bone tumor and soft tissue tumor $(\mathrm{P}<0.0001$, $\mathrm{P}<0.0001, \mathrm{P}=0.0003$, respectively (Fig. 1). Negative surgical margin was also associated with good survival in all patients, in patients with bone tumors, and soft tissue tumors $(\mathrm{P}=0.0002, \mathrm{P}=0.0025$, $\mathrm{P}=0.026$, respectively). $\Delta \mathrm{UR} \geqq 30 \%$ was also associated with good survival in all patients and patients with bone tumor $(\mathrm{P}=0.011$ and $\mathrm{P}=0.047$, respectively) but was marginally associate with good survival in soft tissue tumor ( $\mathrm{P}=0.091)$ (Fig. 2). Histopathological good response were significantly associated with good overall survival in all patients $(\mathrm{P}=0.025)$ but association was marginal in bone tumor $(\mathrm{P}=0.067)$ and insignificant in soft tissue tumor $(\mathrm{P}=0.18)$ (Fig. 3). Both Tc-99m-MIBI uptake ratios before chemotherapy and after the middle course of preoperative chemotherapy were not associated with prognosis in all patients and in both patients with bone tumor and soft tissue tumor ( $\mathrm{P}>0.4$ in all group of patients). 
When analysis was restricted to patients without metastasis, $\Delta \mathrm{UR} \geqq 30 \%$ was significantly associated with good survival in all patients $(\mathrm{P}=0.0056)$ and in patients with bone tumor $(\mathrm{P}=0.005)$, however, association was insignificant in patients with soft tissue tumor $(\mathrm{P}=0.13)$ (Fig. 4). Similarly, histopathological good response was associated with good survival in all patients $(\mathrm{P}=0.0025)$ and in patients with bone tumor $(\mathrm{P}=0.007)$ but not in soft tissue tumor $(\mathrm{P}=0.11)$ (Fig. 5). Sex, age and the site of the primary tumor were not associated with prognosis. Both Tc-99m-MIBI uptake ratios before chemotherapy and after chemotherapy were not associated with prognosis $(\mathrm{P}>0.26$ in all groups of patients).

As shown in Table 2, several variables were significant predictors of overall survival at univariate analysis. Good outcome was associated with absence of metastasis in all patients and in both patients with bone tumor and soft tissue tumor (Hazard Ratio (HR) 5.1, 95\% confidence interval (CI) 2.7-9.4, $\mathrm{P}<0.0001 ; 7.3,2.7-20, \mathrm{P}=0.0001 ; 4.2,1.7-9.7, \mathrm{P}=0.0021$, respectively). Negative surgical margin was associated with good prognosis in all patients and patients with bone tumor but was tended to be associated in patients with soft tissue tumor (HR 3.9, CI 1.7-8.0, $\mathrm{P}=0.0030 ; 4.8,1.3-14, \mathrm{P}=0.019 ; 3.2$, 0.91-8.6, $\mathrm{P}=0.067)$. Good response in Tc-99m-MIBI imaging ( $\Delta \mathrm{UR} \geqq 30 \%$ ) was associated with good prognosis in all patients and patients with bone tumor but was tended to be associated in patients with soft tissue tumor (HR 2.3, CI 1.2-4.7, $\mathrm{P}=0.010$; HR 2.7, CI 1.02-8.5, $\mathrm{P}=0.040$; HR 2.1, CI 0.90-5.5, $\mathrm{P}=0.088$, respectively). Histopathological good response associated with good response in all patients (HR 2.0, CI 1.1-4.0, $\mathrm{P}=0.024)$ but tended to associate in bone tumor (HR 2.3, CI 0.93-6.3, $\mathrm{P}=0.071)$ and insignificantly associated in soft tissue tumor (HR 1.8, CI 0.78-4.7, $\mathrm{P}=0.17)$. The degree of Tc-99m-MIBI uptake ratios before chemotherapy and after the middle course of preoperative chemotherapy did not have association with prognosis in any group of patients.

Multivariate analysis showed that primary metastasis was the most powerful independent predictor of a lethal clinical outcome in MBST and in both bone tumor and soft tissue tumor (HR 4.9, CI 
2.6-9.1, $\mathrm{P}<0.0001$; HR 15, CI 4.9-53, $\mathrm{P}<0.0001$; HR 3.7, CI 1.5-8.9, $\mathrm{P}=0.0069$, respectively). $\Delta \mathrm{UR}$ had a good long-term prognostic value in all patients and in bone tumor (HR 2.2, CI 1.1-4.4, $\mathrm{P}=0.017$; HR 6.0, CI 2.0-22, $\mathrm{P}=0.0009$, respectively) but not in soft tissue tumor (HR 1.5, CI 0.61-4.1, $\mathrm{P}=0.38$ ).

Good disease free survival by Kaplan-Meier analysis was associated with $\Delta \mathrm{UR} \geqq 30 \%$ in all patients $(\mathrm{P}=0.0093)$ and in patients with soft tissue tumor $(\mathrm{P}=0.017)$ but not in patients with bone tumor $(\mathrm{P}=0.19)$ (Fig. 6). Good disease free survival tended to associate with histopathological good response in all patients $(\mathrm{P}=0.057)$ and patients with soft tissue tumor $(\mathrm{P}=0.051)$ (Fig. 7). Both Tc-99m-MIBI uptake ratios before chemotherapy and after chemotherapy did not have association with disease free survival ( $\mathrm{P}>0.36$ in any group of patients).

Representative cases of the patients with good and poor response by Tc-99m-MIBI imaging are shown in Fig. 8 and 9, respectively.

\section{DISCUSSION}

The present study demonstrated for the first time that the tumor response to preoperative chemotherapy defined by the significant reduction of tumor Tc-99m-MIBI uptake from pre-chemotherapy to post mid-course of preoperative chemotherapy ( $\Delta \mathrm{UR} \geqq 30 \%$ ) was not only a predictor of histopathological tumor response but also a significant prognostic factor in MBST. $\Delta U R$ $\geqq 30 \%$ was significantly associated with good overall survival in patients with bone tumor and was associated with good disease free survival in patients with soft tissue tumor.

Recently, Tc-99m-MIBI scintigraphy has been used not only to assess tumor uptake at initial diagnosis but also to assess the effect of preoperative chemotherapy in patients with MBST, because it accumulate largely in mitochondria by its negative trans-membrane potential and the uptake depends on the cell viability and metabolic status.19 Histologic response to preoperative chemotherapy has been recognized as an important prognostic indicator, therefore, it should be appreciated that, as a 
noninvasive surrogate marker of histologic response, Tc-99m-MIBI imaging can be used as a prognostic indicator.

Although MBST are generally chemosensitive tumors and its sensitivity depends on variable tumor subtypes, ${ }^{20-23}$ preoperative chemotherapy is thought to have benefits in improving local control rates and long-term survivals by reducing local tumor aggressiveness, eradicating micrometastasis, and obtaining a safety margin before surgery. It has been proved that the histopathological response to preoperative chemotherapy, defined as $\geq 90 \%$ tumor necrosis, is an important prognostic factor in MBST. However, histopathological evaluation is not always absolutely perfect. Some discrepancies between histopathological and scintigraphic responses might have arisen if viable cells were located at the peripheral part of tumor or scattered inhomogeneously in the necrotic tissue, because the histopathological grade of tumor response to preoperative chemotherapy was not always evaluated based on the surveillance throughout the tumor but evaluated principally using the largest slice of the resected tumor. Radionuclide imaging reflects whole tumor viability as a tracer uptake and would compensate for the potential weakness in the histopathological evaluation. Another limitation of the histologic response assessment is that it is possible only once and only after the completion of the series of the preoperative chemotherapy and surgical resection, usually after 10-15 weeks of initial chemotherapy. In the present study Tc-99m-MIBI imaging was performed at the middle course of preoperative chemotherapy, indicating earlier availability of the information about tumor response to chemotherapy and prognosis.

Traditional radiographic methods to assess response to preoperative chemotherapy, such as CT and MR imaging, has been used to measure volume changes. ${ }^{24,25}$ However, volume change measurement is insensitive method with which to determine chemotherapy responsiveness and prognosis. Both imaging, especially MRI can evaluate various phenomena during tumor regression such as necrosis, hemorrhage, development of granulation tissue, fibrosis etc. ${ }^{26-29}$ For the direct assessment of tumor 
viability, dynamic contrast enhanced MRI could be more precise method, ${ }^{30}$ because it can provide information about tissue perfusion, capillary permeability and hence tumor viability. However, in our knowledge, there is no systematic study whether dynamic MRI has significant value for the assessment of tumor response to preoperative chemotherapy and potential prognostic value.

Unlike morphologic imaging modalities, F-18-FDG PET demonstrated good correlation between a reduction in tumor glucose metabolism after preoperative chemotherapy and necrosis rate in patients with osteosarcoma. ${ }^{31-38}$ It has been evaluated whether the F-18-FDG PET can be a prognostic indicator in 31 patients with osteosarcoma with median follow-up of 2.6 years and has been shown that high maximum standardized uptake value (SUV) before and after the completion of preoperative chemotherapy had association with worse progression-free survival, and post-chemotherapy SUV had association with overall mortality. ${ }^{34}$ Another study with F-18-FDG PET in 40 osteosarcoma demonstrated that only post-chemotherapy SUV was associated with progression free survival. ${ }^{36}$ In both of the studies, the change of FDG uptake from pre- to post-chemotherapy was not associated with prognosis. In 36 patients with Ewing sarcoma, post-chemotherapy SUV and ratio of post-chemotherapy SUV to pre-chemotherapy SUV was fairly concordant with histologic response but only post-chemotherapy SUV was associated with outcome. ${ }^{37}$ In 46 patients with soft tissue sarcoma, change in SUV after chemotherapy was correlated with histologic change, disease recurrence and overall survival. ${ }^{38}$ On the other hand, in 14 patients with MBST, the pathologically determined degree of necrosis post-chemotherapy was concordant with PET-assessed European Organization for Research and Treatment of Cancer classification of response in $57.1 \%$ of the cases. A significant number of patients had discrepancies, which may be in part explained by chemotherapy-induced inflammation. ${ }^{39}$ In the present study, both of the degree of Tc-99m-MIBI uptake ratios before and after 3 cycle of preoperative chemotherapy did not have association with prognosis, but the change of the Tc-99m-MIBI uptake from pre- to post-chemotherapy was an 
indicator of the prognosis. These differences among the PET studies and Tc-99m-MIBI study might arise from the difference in patient selection and used tracer.

There are several clinical utilities of Tc-99m-MIBI imaging in the management of MBST. As a surrogate marker of histologic response, high $\triangle \mathrm{UR}$ in Tc-99m-MIBI imaging can identify the patients with good response to chemotherapy and permit less aggressive limb-sparing surgery. On the other hand, low $\Delta \mathrm{UR}$ may indicate the patients would have unfavorable histologic response during the mid course of preoperative chemotherapy, leading to an alteration in the regimen of the subsequent chemotherapy or more aggressive surgery.

Although F-18-FDG PET may have several potential clinical merits such as good ability to detect smaller lesions and distant metastasis, Tc-99m-MIBI has practical advantage over F-18-FDG PET in daily practice because of its continuous availability as a kit-based agent with Mo-99-Tc-99m generator system. In addition, imaging with gamma camera can be performed without fasting and be free from the influence of the serum glucose level, and the imaging cost is low compared with PET. The spatial resolution of Tc-99m-MIBI imaging with gamma camera was lower than that of F-18-FDG PET, however, this issue is not considered as a significant disadvantage because MBST is usually large enough for imaging and analysis.

When we analyzed bone and soft tissue tumors separately, the reduction of the tracer uptake was also associated with overall survival in bone tumors but only tended to be associated with prognosis in soft tissue tumors $(\mathrm{p}=0.091)$. On the other hand, the reduction of the tracer uptake was significantly associated with disease free survival in patients with soft tissue tumors but not in patients with bone tumors $(\mathrm{P}=0.19)$. Further evaluation might be needed in large number of patients. As a marker of tumor viability, we used Tc-99m-MIBI uptake in the early image rather than uptake in delayed image and retention rate in dual-phase images. Tc-99m-MIBI has been proved to be one of 
the substrate of P-glycoprotein, which is a product of the human multidrug resistance related protein (MPR).40,41 It was also showed that delayed Tc-99m-MIBI uptake was related to P-glycoprotein expression, while early uptake was not,24 and the early uptake was comparable to early T1-201 uptake in patients with MBST.11, 12 Therefore, Tc-99m-MIBI early uptake seems to reflect tumor viability more properly than delayed uptake and retention rate.

Preoperative chemotherapy has done with caffeine-assisted chemotherapy in this study, because caffeine can safely enhance the cytocidal effects of anticancer drugs through its DNA repair-inhibiting effects.8, 17 Although, whether caffeine directly change the uptake of Tc-99m-MIBI in vivo is not reported yet, in-vitro study demonstrated that caffeine did not significantly alter Tc-99m-MIBI net cell uptake.19 Therefore, caffeine may not directly influence the process of Tc-99m-MIBI accumulation.

\section{CONCLUSION}

The change of Tc-99m-MIBI uptake from pre-chemotherapy to post middle course of preoperative chemotherapy $(\Delta \mathrm{UR})$ is a predictor of overall survival in patients with malignant bone tumors and a predictor of disease free survival in patients with soft tissue tumors. In the subset of patients without metastasis at initial diagnosis, $\Delta \mathrm{UR}$ is also an indicator of overall survival in patients with bone tumor.

\section{ACKNOWLEDGMENTS}

The authors did not receive funding or grants in support of this research. No benefits in any form have been received or will be received from a commercial party related directly or indirectly to the subject of this article. 


\section{REFERENCE}

1. Reddick WE, Wang S, Xiong X, et al. Dynamic magnetic resonance imaging of regional contrast access as an additional prognostic factor in pediatric osteosarcoma. Cancer. 2001;91: 2230-2237.

2. Hudson M, Jaffe MR, Jaffe N, et al. Pediatric osteosarcoma: therapeutic strategies, results, and prognostic factors derived from a 10-year experience. J Clin Oncol. 1990;8: 1988-1997.

3. Kunisada T, Ozaki T, Kawai A, et al. Imaging assessment of the responses of osteosarcoma patients to preoperative chemotherapy: angiography compared with thallium-201 scintigraphy. Cancer. 1999;86: 949-956.

4. Bonnerot V, Charpentier A, Frouin F, et al. Factor analysis of dynamic magnetic resonance imaging in predicting the response of osteosarcoma to chemotherapy. Invest Radiol. 1992;27: 847-855.

5. Hanna SL, Parham DM, Fairclough DL, et al. Assessment of osteosarcoma response to preoperative chemotherapy using dynamic FLASH gadolinium-DTPA-enhanced magnetic resonance mapping. Invest Radiol. 1992;27: 367-373.

6. Tsuchiya H, Tomita K, Minematsu K, et al. Limb salvage using distraction osteogenesis. A classification of the technique. J Bone Joint Surg Br. 1997;79: 403-411.

7. Jaffe N, Patel SR, Benjamin RS. Chemotherapy in osteosarcoma. Basis for application and antagonism to implementation; early controversies surrounding its implementation. Hematol Oncol Clin North Am. 1995;9: 825-840.

8. Tsuchiya H, Tomita K, Mori Y, et al. Marginal excision for osteosarcoma with caffeine assisted chemotherapy. Clin Orthop Relat Res. 1999: 27-35.

9. Eilber FR, Morton DL, Eckardt J, et al. Limb salvage for skeletal and soft tissue sarcomas. Multidisciplinary preoperative therapy. Cancer. 1984;53: 2579-2584.

10. Aktolun C, Bayhan H, Kir M. Clinical experience with Tc-99m MIBI imaging in patients with malignant tumors. Preliminary results and comparison with Tl-201. Clin Nucl Med. 1992;17: 171-176.

11. Taki J, Higuchi T, Sumiya H, et al. Prediction of final tumor response to preoperative chemotherapy by Tc-99m MIBI imaging at the middle of chemotherapy in malignant bone and soft tissue tumors: comparison with Tl-201 imaging. J Orthop Res. 2008;26: 411-418.

12. Taki J, Inaki A, Wakabayashi H, et al. Early prediction of histopathological tumor response to preoperative chemotherapy by Tc-99m MIBI imaging in bone and soft tissue sarcomas. Clin Nucl Med. 2010;35: 154-159.

13. Soderlund V, Larsson SA, Bauer HC, et al. Use of 99mTc-MIBI scintigraphy in the evaluation of the response of osteosarcoma to chemotherapy. Eur J Nucl Med. 1997;24: 511-515.

14. Moustafa H, Riad R, Omar W, et al. 99mTc-MIBI in the assessment of response to chemotherapy and detection of recurrences in bone and soft tissue tumours of the extremities. Q J Nucl Med. 2003;47: 51-57. 
15. Kager L, Zoubek A, Potschger U, et al. Primary metastatic osteosarcoma: presentation and outcome of patients treated on neoadjuvant Cooperative Osteosarcoma Study Group protocols. J Clin Oncol. 2003;21: 2011-2018.

16. Bielack SS, Kempf-Bielack B, Delling G, et al. Prognostic factors in high-grade osteosarcoma of the extremities or trunk: an analysis of 1,702 patients treated on neoadjuvant cooperative osteosarcoma study group protocols. J Clin Oncol. 2002;20: 776-790.

17. Tsuchiya H, Tomita K, Mori Y, et al. Caffeine-assisted chemotherapy and minimized tumor excision for nonmetastatic osteosarcoma. Anticancer Res. 1998;18: 657-666.

18. Rosen G, Marcove RC, Huvos AG, et al. Primary osteogenic sarcoma: eight-year experience with adjuvant chemotherapy. J Cancer Res Clin Oncol. 1983;106 Suppl: 55-67.

19. Piwnica-Worms D, Kronauge JF, Chiu ML. Uptake and retention of hexakis (2-methoxyisobutyl isonitrile) technetium(I) in cultured chick myocardial cells. Mitochondrial and plasma membrane potential dependence. Circulation. 1990;82: 1826-1838.

20. Antman KH. Adjuvant therapy of sarcomas of soft tissue. Semin Oncol. 1997;24: 556-560.

21. Sarcoma Meta-analysis Collaboration. Adjuvant chemotherapy for localised resectable soft-tissue sarcoma of adults: meta-analysis of individual data. Lancet. 1997;350: 1647-1654.

22. Frustaci S, Gherlinzoni F, De Paoli A, et al. Adjuvant chemotherapy for adult soft tissue sarcomas of the extremities and girdles: results of the Italian randomized cooperative trial. J Clin Oncol. 2001;19: 1238-1247.

23. Petrioli R, Coratti A, Correale P, et al. Adjuvant epirubicin with or without Ifosfamide for adult soft-tissue sarcoma. Am J Clin Oncol. 2002;25: 468-473.

24. Aisen AM, Martel W, Braunstein EM, et al. MRI and CT evaluation of primary bone and soft-tissue tumors. AJR Am J Roentgenol. 1986;146: 749-756.

25. Zimmer WD, Berquist TH, McLeod RA, et al. Bone tumors: magnetic resonance imaging versus computed tomography. Radiology. 1985;155: 709-718.

26. Pan G, Raymond AK, Carrasco $\mathrm{CH}$, et al. Osteosarcoma: MR imaging after preoperative chemotherapy. Radiology. 1990;174: 517-526.

27. de Baere T, Vanel D, Shapeero LG, et al. Osteosarcoma after chemotherapy: evaluation with contrast material-enhanced subtraction MR imaging. Radiology. 1992;185: 587-592.

28. Van der Woude HJ, Bloem JL, Verstraete KL, et al. Osteosarcoma and Ewing's sarcoma after neoadjuvant chemotherapy: value of dynamic MR imaging in detecting viable tumor before surgery. AJR Am J Roentgenol. 1995; 165: 593-598.

29. Ongolo-Zogo P, Thiesse P, Sau J, et al. Assessment of osteosarcoma response to neoadjuvant chemotherapy: comparative usefulness of dynamic gadolinium-enhanced spin-echo magnetic resonance imaging and technetium-99m skeletal angioscintigraphy. Eur Radiol. 1999;9: 907-914.

30. Dyke JP, Panicek DM, Healey JH, et al. Osteogenic and Ewing sarcomas: estimation of necrotic fraction during induction chemotherapy with dynamic contrast-enhanced MR imaging. Radiology. 2003;228: 271-278. 
31. Hawkins DS, Rajendran JG, Conrad EU, et al. Evaluation of chemotherapy response in pediatric bone sarcomas by [F-18]-fluorodeoxy-D-glucose positron emission tomography. Cancer. 2002;94: 3277-3284.

32. Schulte M, Brecht-Krauss D, Werner M, et al. Evaluation of neoadjuvant therapy response of osteogenic sarcoma using FDG PET. J Nucl Med. 1999;40: 1637-1643.

33. Benz MR, Allen-Auerbach MS, Eilber FC, et al. Combined assessment of metabolic and volumetric changes for assessment of tumor response in patients with soft-tissue sarcomas. J Nucl Med. 2008;49: 1579-1584.

34. Costelloe CM, Macapinlac HA, Madewell JE, et al. 18F-FDG PET/CT as an indicator of progression-free and overall survival in osteosarcoma. J Nucl Med. 2009;50: 340-347.

35. Cheon GJ, Kim MS, Lee JA, et al. Prediction model of chemotherapy response in osteosarcoma by 18F-FDG PET and MRI. J Nucl Med. 2009;50: 1435-1440.

36. Hawkins DS, Conrad EU, Butrynski JE, et al. [F-18]-fluorodeoxy-D-glucose-positron emission tomography response is associated with outcome for extremity osteosarcoma in children and young adults. Cancer. 2009; 115: 3519-3525.

37. Hawkins DS, Schuetze SM, Butrynski JE, et al. [18F]Fluorodeoxyglucose positron emission tomography predicts outcome for Ewing sarcoma family of tumors. J Clin Oncol. 2005;23: 8828-8834.

38. Schuetze SM, Rubin BP, Vernon C, et al. Use of positron emission tomography in localized extremity soft tissue sarcoma treated with neoadjuvant chemotherapy. Cancer. 2005;103: 339-348.

39. Iagaru A, Masamed R, Chawla SP, et al. F-18 FDG PET and PET/CT evaluation of response to chemotherapy in bone and soft tissue sarcomas. Clin Nucl Med. 2008;33: 8-13.

40. Taki J, Sumiya H, Asada N, et al. Assessment of P-glycoprotein in patients with malignant bone and soft-tissue tumors using technetium-99m-MIBI scintigraphy. J Nucl Med. 1998;39: 1179-1184.

41. Burak Z, Moretti JL, Ersoy O, et al. 99mTc-MIBI imaging as a predictor of therapy response in osteosarcoma compared with multidrug resistance-associated protein and P-glycoprotein expression. J Nucl Med. 2003;44: 1394-1401. 


\section{Figure Legends}

\section{Figure 1.}

Kaplan-Meier curves of primary metastasis and overall survival with metastasis (solid line) and absence of metastasis (dashed line). (a) In all patients, primary metastasis are associated with worse overall survival $(\mathrm{P}<0.0001)$. (b) In patients with bone tumor, primary metastasis is associated with worse overall survival, too $(\mathrm{P}<0.0001)$. (c) In patients with soft tissue tumor, primary metastasis is also associated with worse overall survival $(\mathrm{P}=0.0003)$.

\section{Figure 2.}

Kaplan-Meier curves of the \% reduction of Tc-99m-MIBI uptake ratio $(\Delta \mathrm{UR})$ and overall survival with $\Delta \mathrm{UR}<30 \%$ (solid line) and $\Delta \mathrm{UR} \geqq 30 \%$ (dashed line). (a) In all patients with $\Delta \mathrm{UR} \geqq 30 \%$ is associated with good overall survival $(\mathrm{P}=0.011)$. (b) In patients with bone tumor, $\Delta \mathrm{UR} \geqq 30 \%$ is also associated with good overall survival $(\mathrm{P}=0.047)$. (c) In patients with soft tissue tumor, $\Delta \mathrm{UR} \geqq 30 \%$ tended to be associated with good overall survival $(\mathrm{P}=0.091)$.

\section{Figure 3.}

Kaplan-Meier curves of the histopathological response and overall survival with poor histopathological response (solid line) and good histopathological response (dashed line). (a) In all patients, good histopathological response is associated with good overall survival ( $\mathrm{P}=0.025)$. (b) In patients with bone tumor, good histopathological response tended to be associated with good overall survival ( $\mathrm{P}=0.067)$. (c) In patients with soft tissue tumor, good histopathological response is not associated with good overall survival $(\mathrm{P}=0.18)$.

\section{Figure 4.}

Kaplan-Meier curves of \% reduction of Tc-99m-MIBI uptake ratio ( $\Delta \mathrm{UR})$ and overall survival with 
$\Delta \mathrm{UR}<30 \%$ (solid line) and $\Delta \mathrm{UR} \geqq 30 \%$ (dashed line) in patients without primary metastasis. (a) In all patients, $\Delta \mathrm{UR} \geqq 30 \%$ is associated with good overall survival ( $\mathrm{P}=0.0056)$. (b) In patients with bone tumor, $\Delta \mathrm{UR} \geqq 30 \%$ is associated with good overall survival ( $\mathrm{P}=0.005)$. (c) In patients with soft tissue tumor, $\Delta \mathrm{UR} \geqq 30 \%$ is not associated with good overall survival $(\mathrm{P}=0.13)$.

\section{Figure 5.}

Kaplan-Meier curves of the histopathological response and overall survival with poor histopathological response (solid line) and good histopathological response (dashed line) in patients without primary metastasis. (a) In all patients, good histopathological response are associated with good overall survival $(\mathrm{P}=0.0025)$. (b) In patients with bone tumor, good histopathological response tended to be associated with good overall survival $(\mathrm{P}=0.007)$. (c) In patients with soft tissue tumor, good histopathological response is not associated with good overall survival $(\mathrm{P}=0.11)$.

\section{Figure 6.}

Kaplan-Meier curves of \% reduction of Tc-99m-MIBI uptake ratio ( $\Delta$ UR) and disease free survival after surgical operation with $\Delta \mathrm{UR}<30 \%$ (solid line) and $\Delta \mathrm{UR} \geqq 30 \%$ (dashed line). (a) In all patients, $\Delta \mathrm{UR} \geqq 30 \%$ are associated with good disease free survival ( $\mathrm{P}=0.0093$ ). (b) In patients with bone tumor, $\Delta \mathrm{UR} \geqq 30 \%$ is not associated with good disease free survival ( $\mathrm{P}=0.19)$. (c) In patients with soft tissue tumor, $\Delta \mathrm{UR} \geqq 30 \%$ is associated with good disease free survival $(\mathrm{P}=0.017)$.

\section{Figure 7.}

Kaplan-Meier curves of the histopathological response and disease free survival with poor histopathological response (solid line) and good histopathological response (dashed line). (a) In all patients, good histopathological response tended to be associated with good disease free survival $(\mathrm{P}=0.057)$. (b) In patients with bone tumor, good histopathological response is not associated with 
good disease free survival ( $\mathrm{P}=0.36)$. (c) In patients with soft tissue tumor, good histopathological response tended to be associated with good disease free survival $(\mathrm{P}=0.051)$.

\section{Figure 8.}

Anterior Tc-99m-MIBI image in a patient with osteosarcoma of the right proximal humerus. High uptake of Tc-99m-MIBI in the tumor before preoperative chemotherapy (a) almost disappeared after 3 cycle of preoperative chemotherapy $(\Delta \mathrm{UR}=43 \%)$ (b). After 5 cycle of chemotherapy, tumor resection was performed and complete hisopathological response (100\% necrosis) was observed. The patient is alive with no local recurrence or metastasis 9 years after the chemotherapy and operation.

\section{Figure 9.}

Anterior Tc-99m-MIBI image in a patient with osteosarcoma of the right distal femur. High uptake of Tc-99m-MIBI in the tumor before preoperative chemotherapy (a) decreased slightly after 3 cycle of preoperative chemotherapy ( $\Delta \mathrm{UR}=21 \%$ ) (b). After 5 cycle of chemotherapy, tumor resection was performed and poor hisopathological response (necrosis $<90 \%$ ) was observed. The patient succumbed to the disease 29 months after the chemotherapy and operation. 
Table 1. Histopathological response compared with the change of Tc-99m-MIBI uptake from pre-chemotherapy to after 3cycle of chemotherapy

Number of patients

\begin{tabular}{ccc} 
Tumor necrosis & $\geq 90 \%$ & $<90 \%$ \\
\hline$\Delta \mathrm{UR} \geq 30 \%$ & 32 (B:17, S:15) & 4 (B: 0, S: 4) \\
$\Delta \mathrm{UR}<30 \%$ & 7 (B: 4, S: 3) & 45 (B:19, S:26) \\
\hline
\end{tabular}

$\Delta U R$ indicates $\%$ reduction of Tc-99m-MIBI uptake ratio from pre-chemotherapy to after 3 cycle of chemotherapy; $B$, bone tumor; S, soft tissue tumor. 
Table 2. Overall Survival Estimated by Univariate Cox Regression Analysis in Patients with Bone Tumor and in Patients with Soft Tissue Tumor

\begin{tabular}{|c|c|c|c|c|c|c|}
\hline \multirow[b]{2}{*}{ Variable } & \multicolumn{2}{|l|}{ All patients } & \multicolumn{2}{|l|}{ Bone Tumor } & \multicolumn{2}{|c|}{ Soft Tissue Tumor } \\
\hline & $\mathrm{HR}(\mathrm{CI})$ & P-value & $\mathrm{HR}(\mathrm{CI})$ & P-value & $\mathrm{HR}(\mathrm{CI})$ & P-value \\
\hline Metastasis at presentation & $5.1 \quad(2.7-9.4)$ & $<0.0001$ & $7.3 \quad(2.7-20)$ & 0.0001 & $4.2(1.7-9.7)$ & 0.0021 \\
\hline Poor response in MIBI & $2.3 \quad(1.2-4.7)$ & 0.010 & $2.7 \quad(1.02-8.5)$ & 0.040 & $2.1 \quad(0.90-5.5)$ & 0.088 \\
\hline UR before chemotherapy & $0.80(0.45-1.5)$ & 0.47 & $0.60(0.22-1.6)$ & 0.32 & $0.99(0.43-2.2)$ & 0.98 \\
\hline UR after chemotherapy & $0.78(0.42-1.5)$ & 0.43 & $1.02(0.41-2.8)$ & 0.96 & $0.60(0.27-1.5)$ & 0.25 \\
\hline Poor response in pathology & $2.0 \quad(1.1-4.0)$ & 0.024 & $2.3(0.93-6.3)$ & 0.071 & $1.8 \quad(0.78-4.7)$ & 0.17 \\
\hline Surgical margin $(\mathrm{P} / \mathrm{N})$ & $3.9 \quad(1.7-8.0)$ & 0.0030 & $4.8 \quad(1.3-14)$ & 0.019 & $3.2(0.91-8.6)$ & 0.067 \\
\hline Sex (Male/ Female) & $0.71(0.34-1.4)$ & 0.32 & $0.84(0.27-2.2)$ & 0.73 & $0.62(0.23-1.5)$ & 0.30 \\
\hline $\operatorname{Age}(40 \leq />)$ & $0.95(0.45-1.8)$ & 0.88 & $0.79(0.35-1.7)$ & 0.11 & $1.4 \quad(0.07-8.5)$ & 0.73 \\
\hline Tumor site (truncal / ext) & $0.67(0.35-1.39)$ & 0.70 & $0.66(0.24-2.4)$ & 0.48 & $0.74(0.32-1.9)$ & 0.52 \\
\hline
\end{tabular}

$H R$ indicates hazard ratio; $C I, 95 \%$ confidence interval; $U R$, uptake ratio; $P / N$, positive/negative; ext, extremity 
Figure 1.

a.

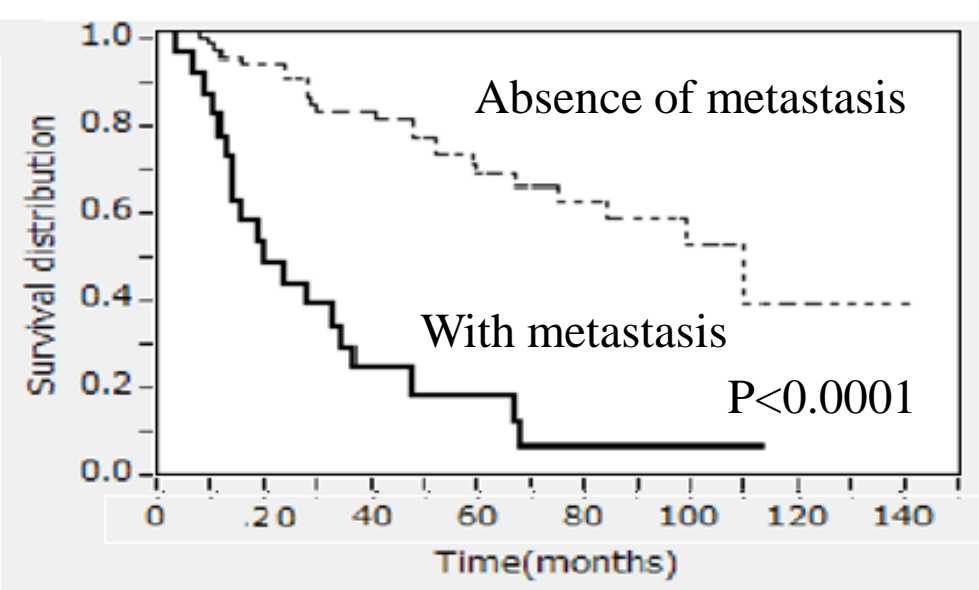

b.

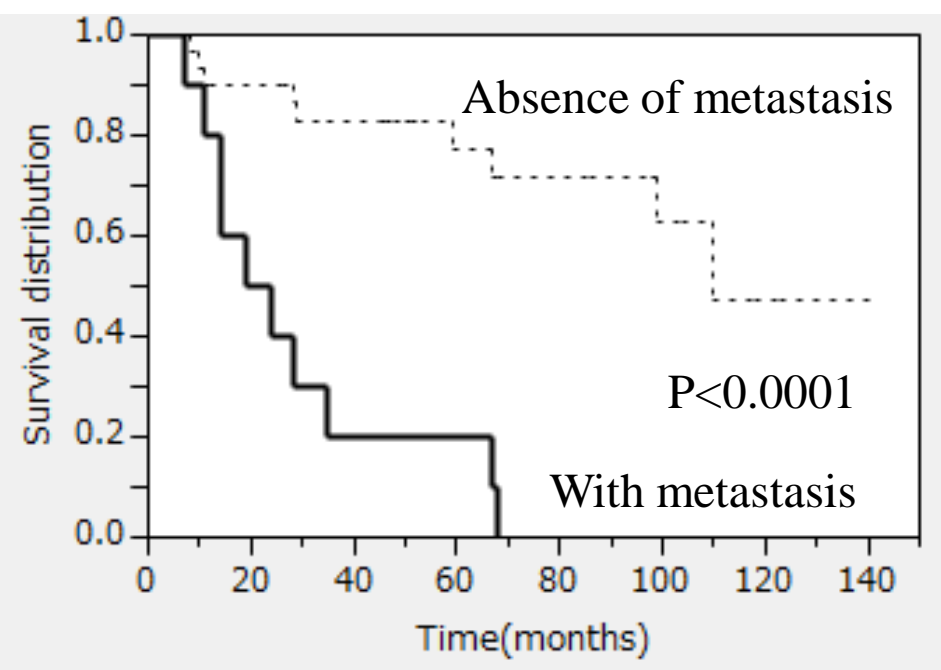

c.

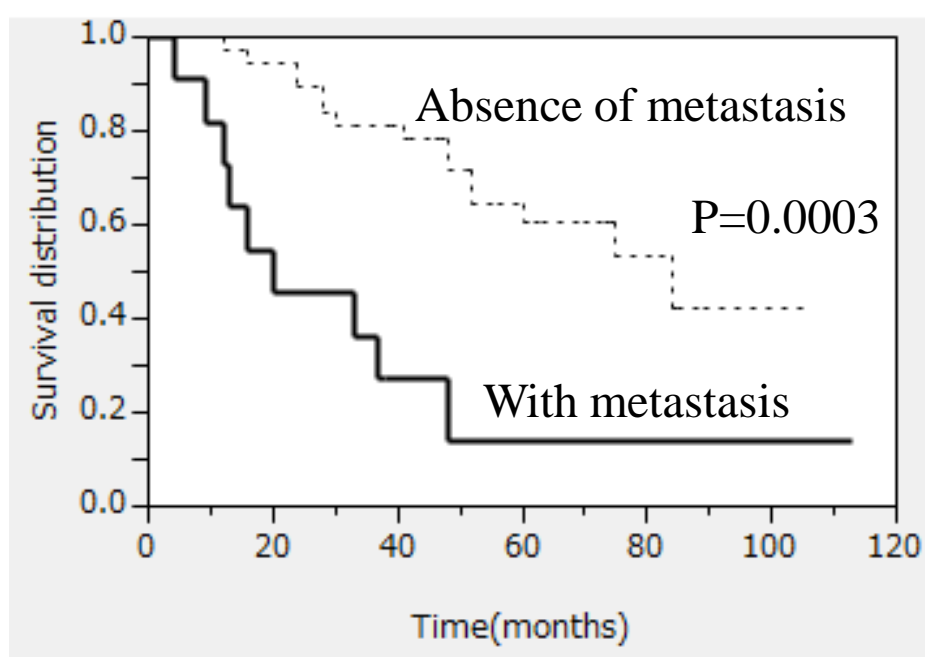


Figure 2.

a.

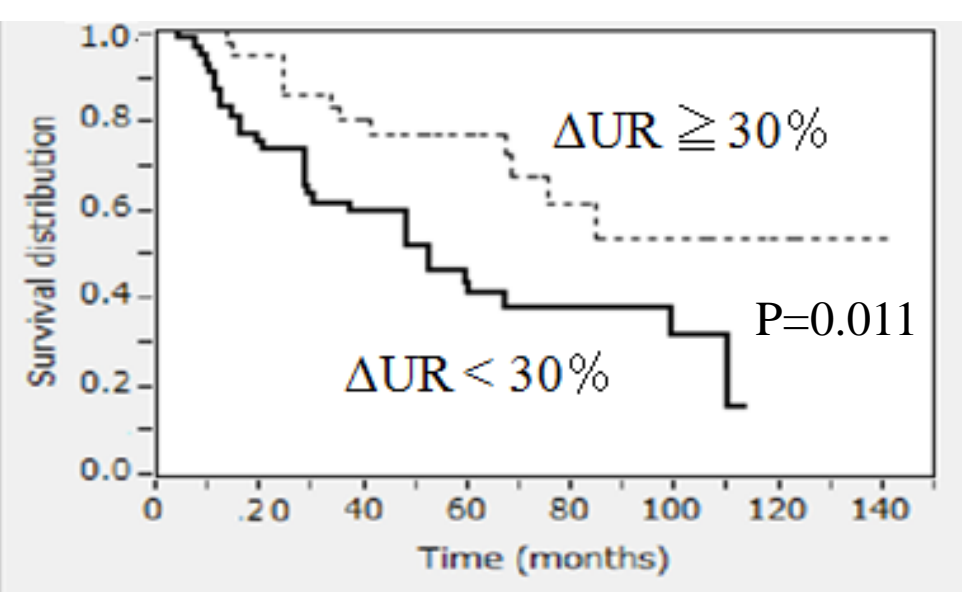

b.

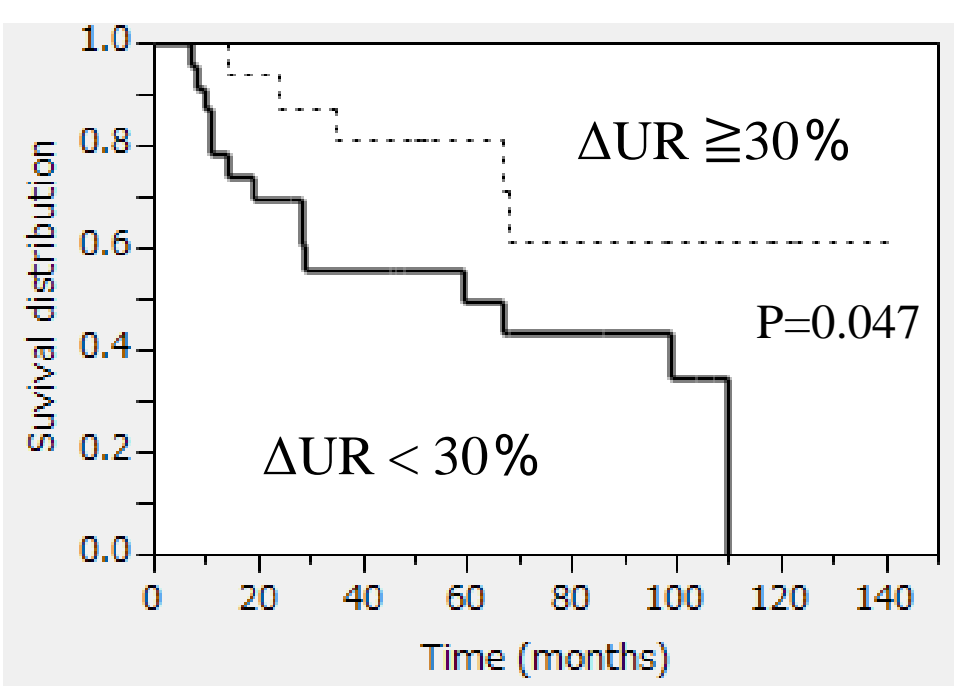

c.

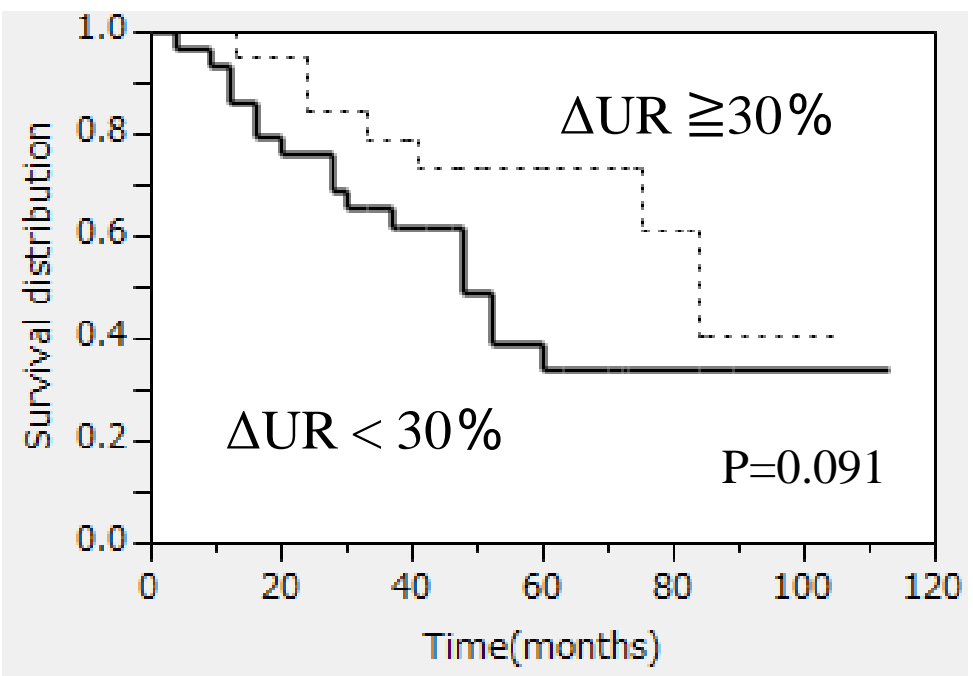


Figure 3.

a.

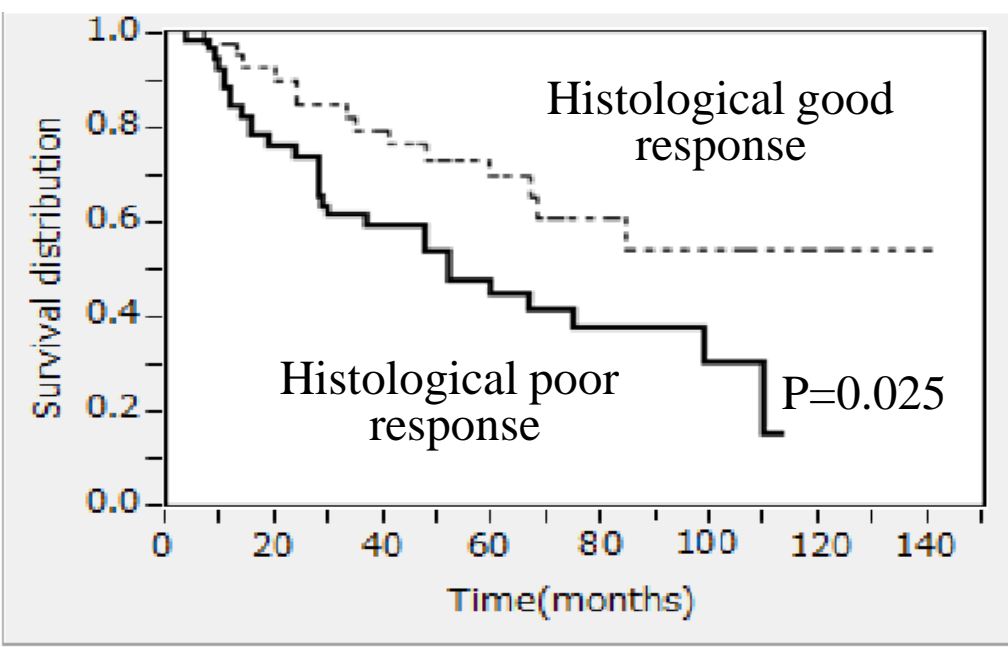

b.

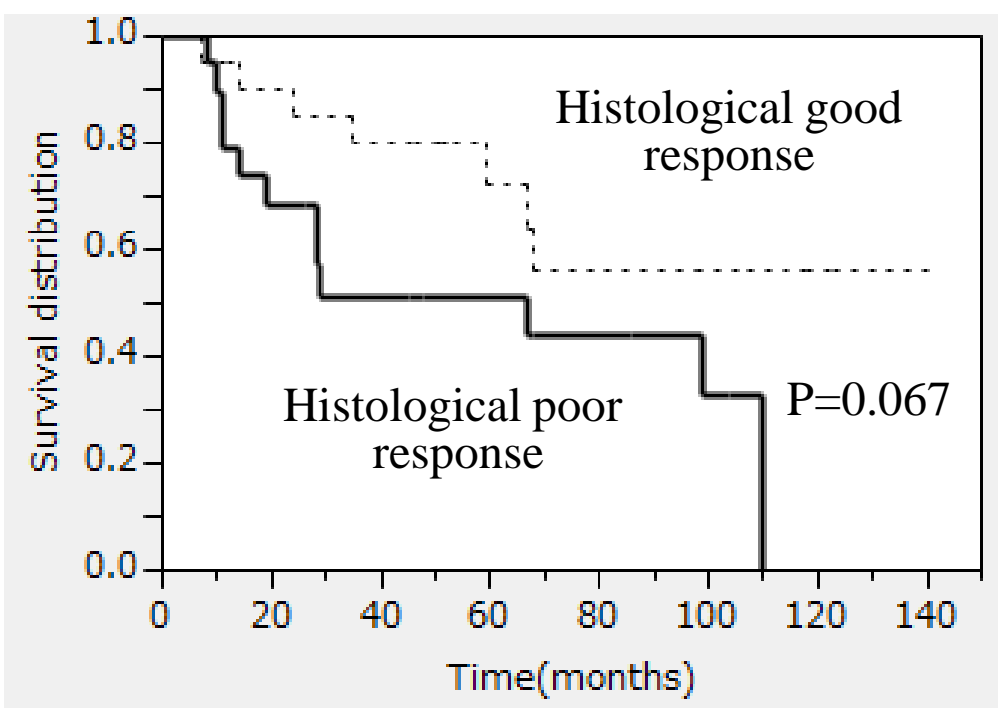

C.

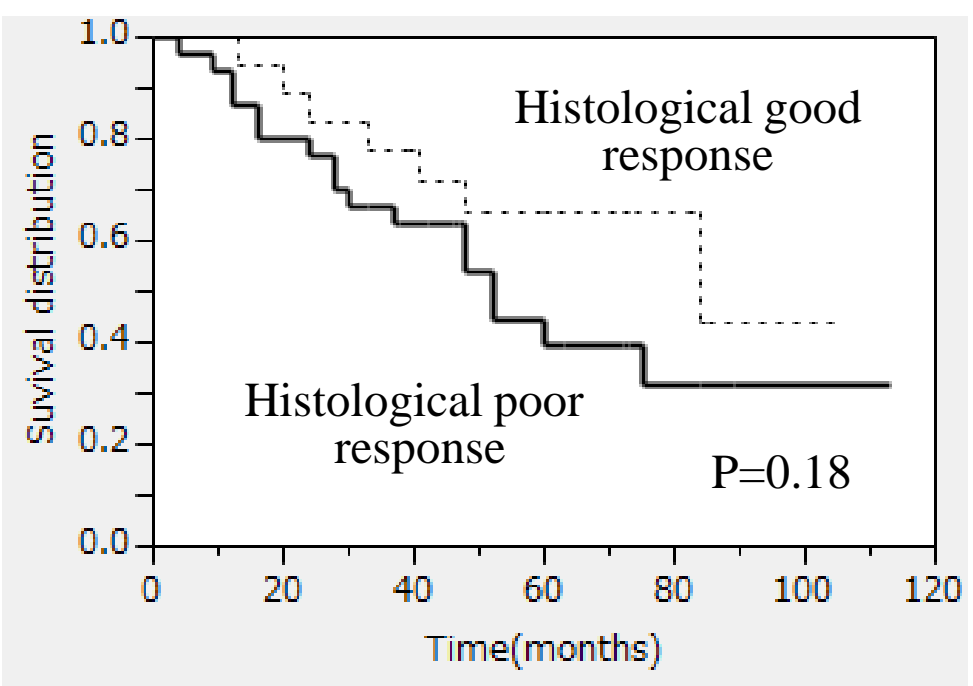


Figure 4.

a.

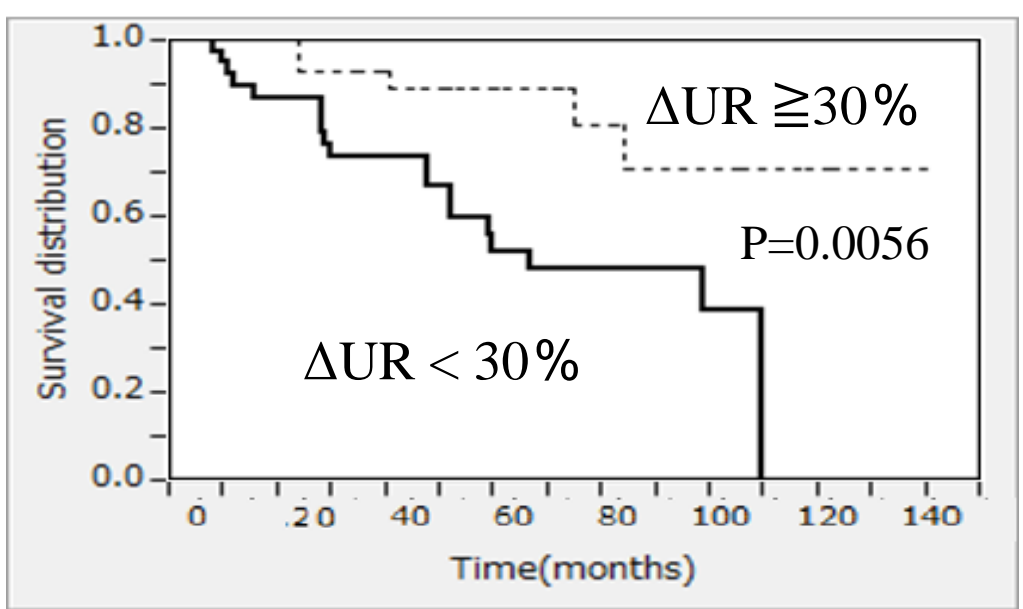

b.

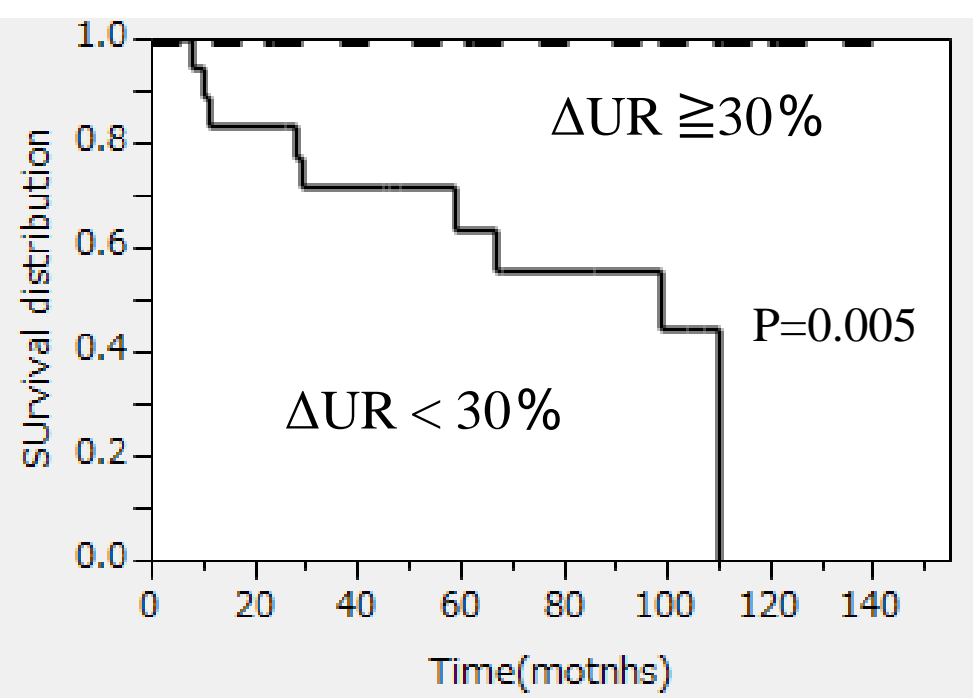

C.

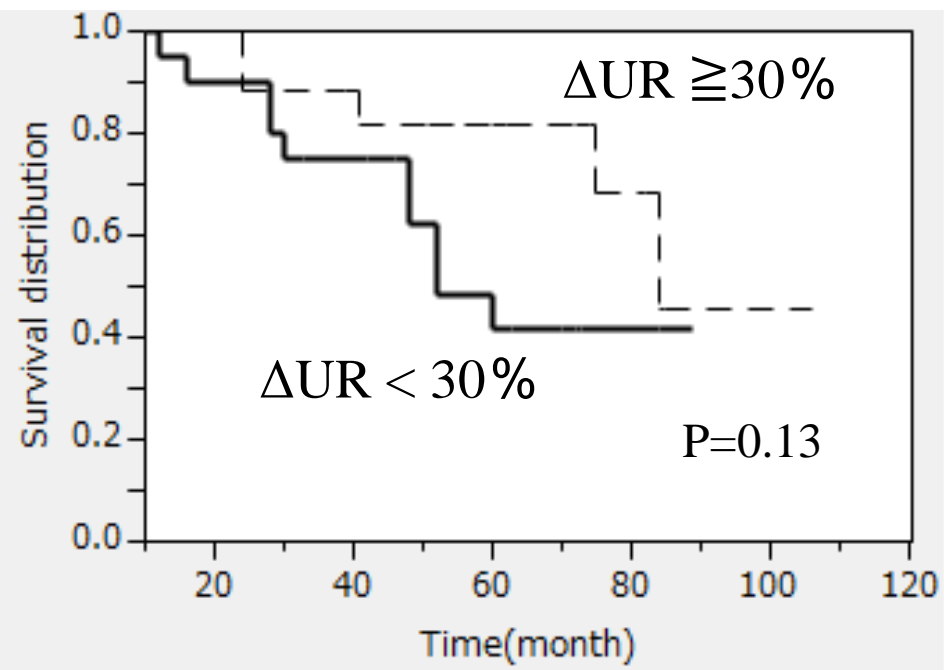


Figure 5.

a.

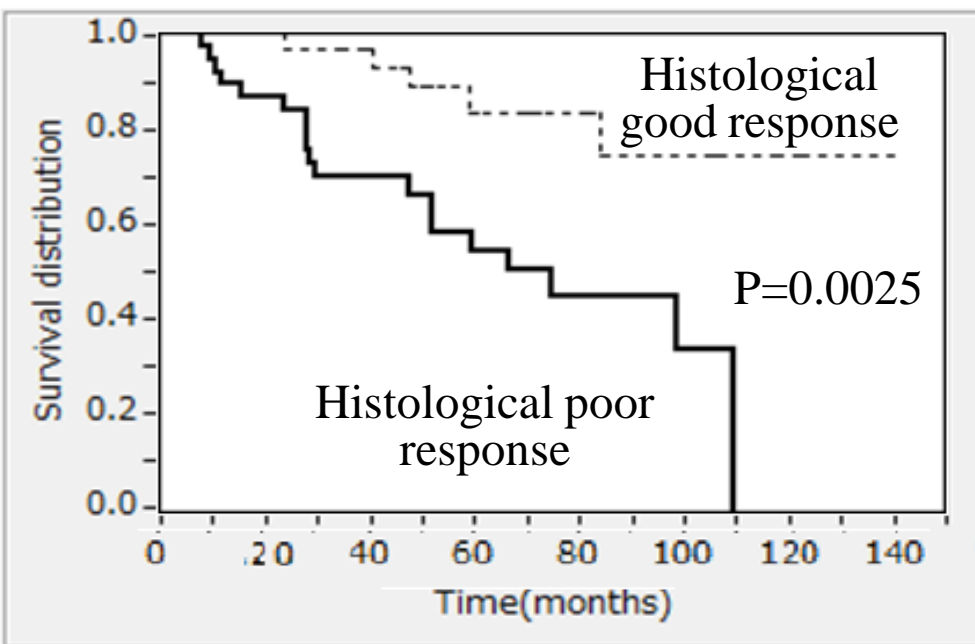

b.

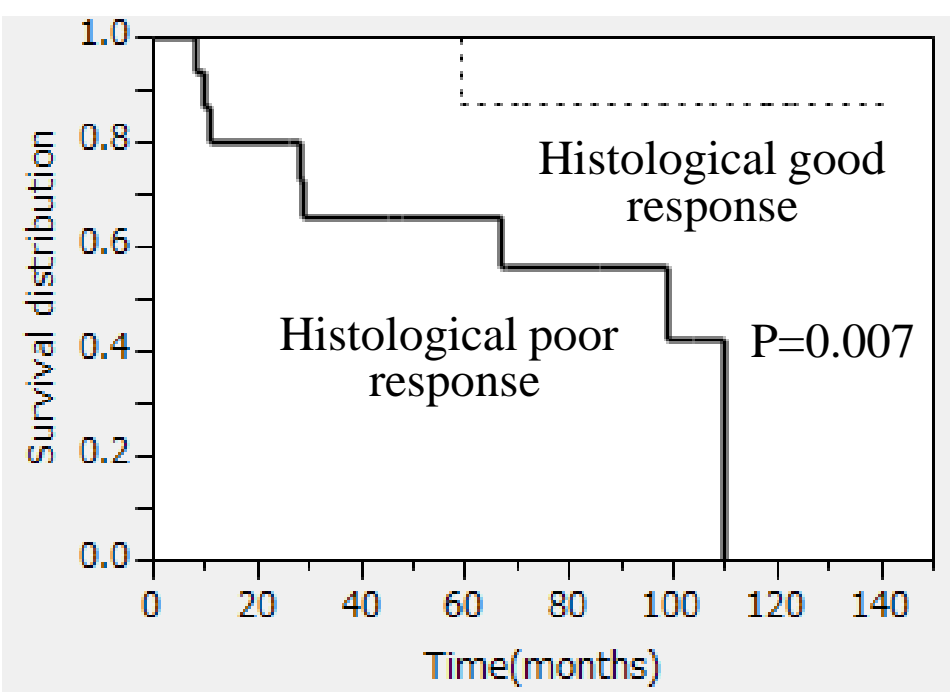

C.

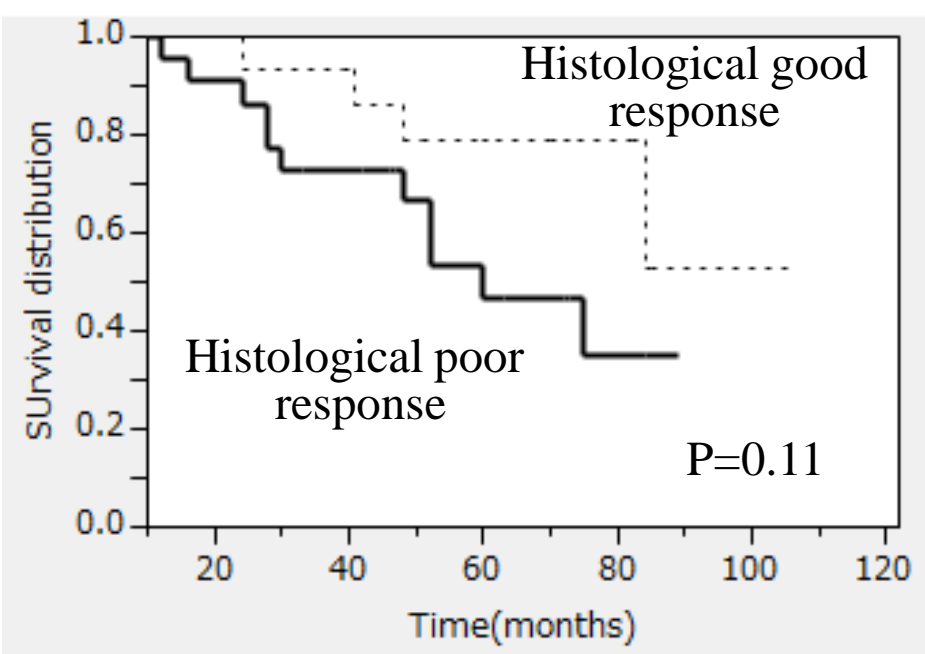




\section{Figure 6.}

a.

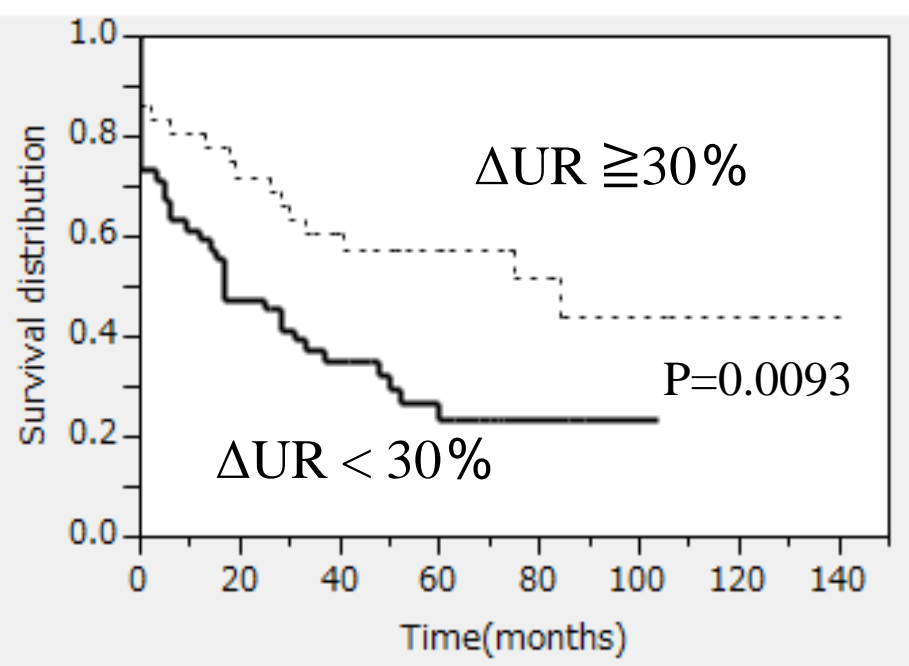

b.

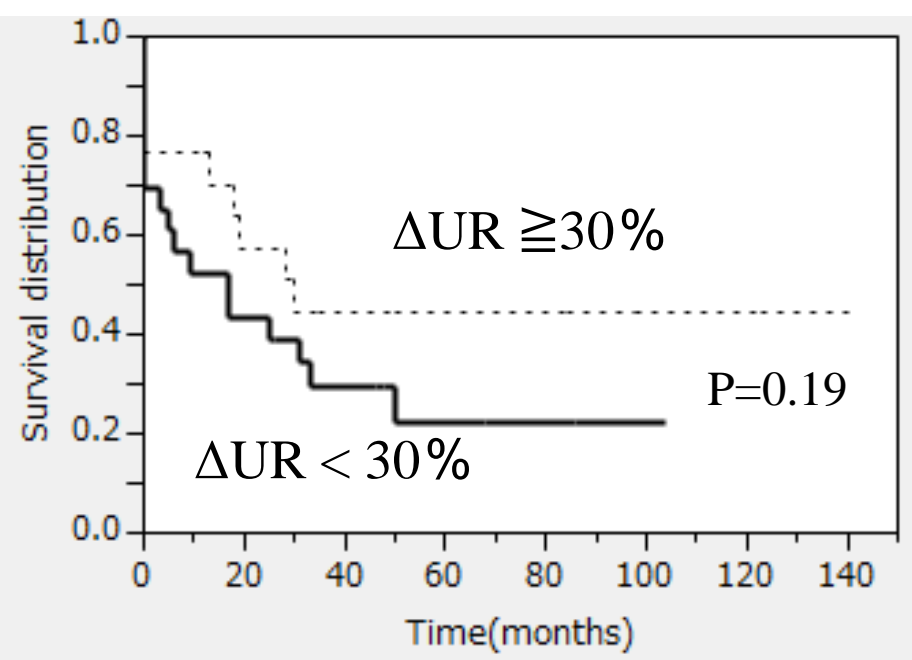

c.

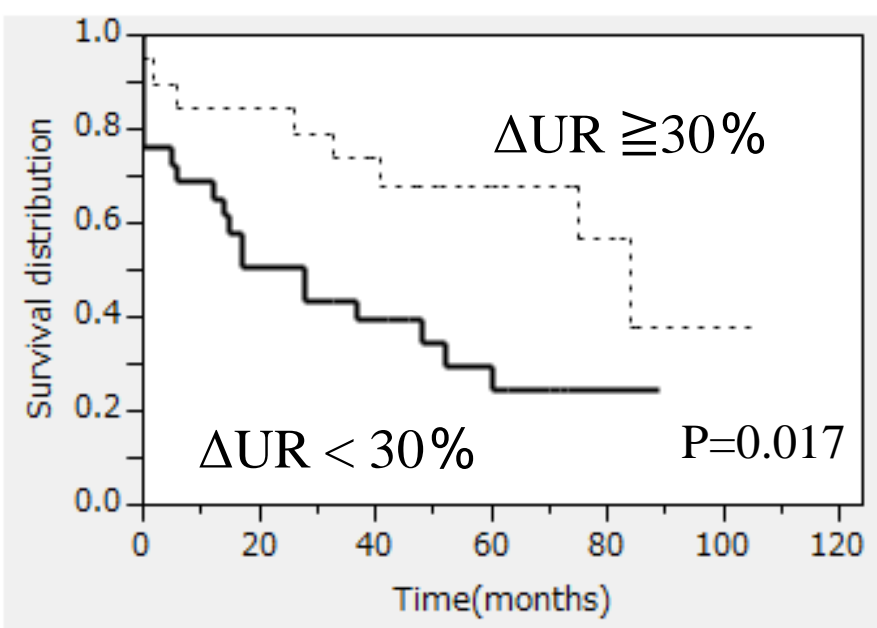




\section{Figure 7.}

a.

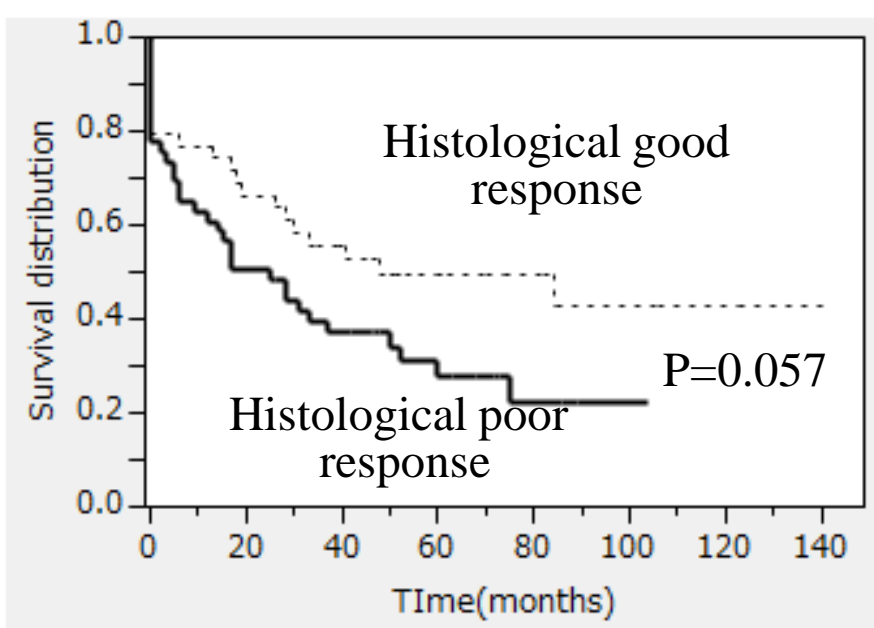

b.

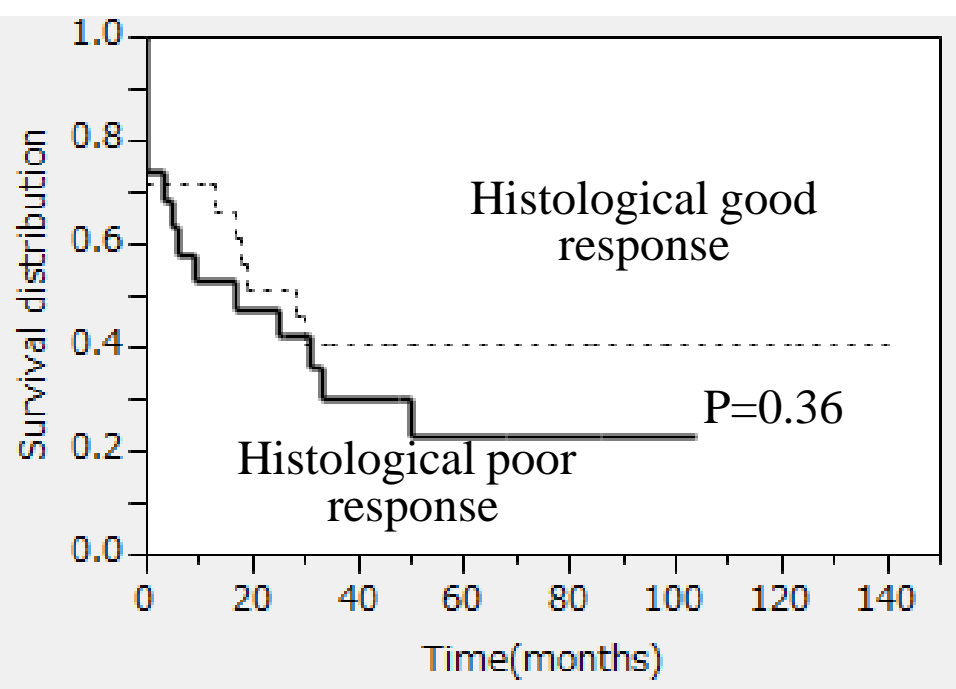

c.

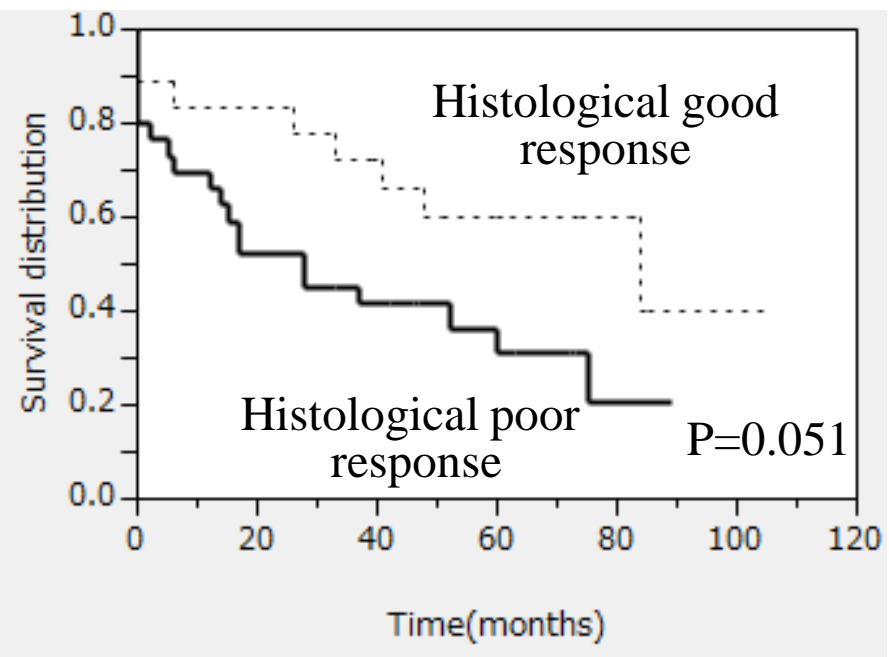


Figure 8.

a.

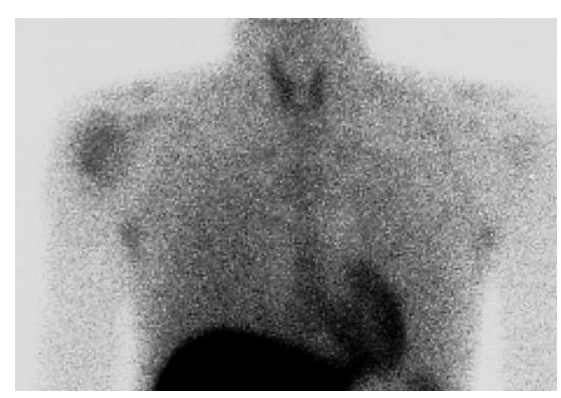

b.

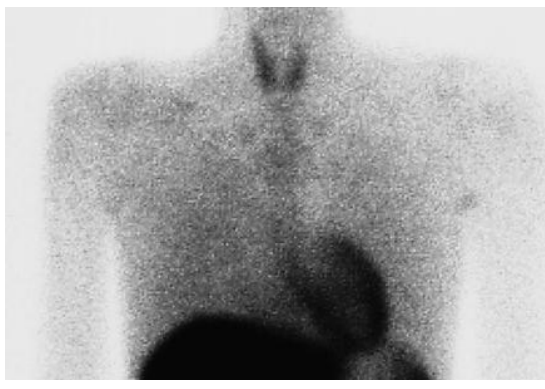


Figure 9.

a.

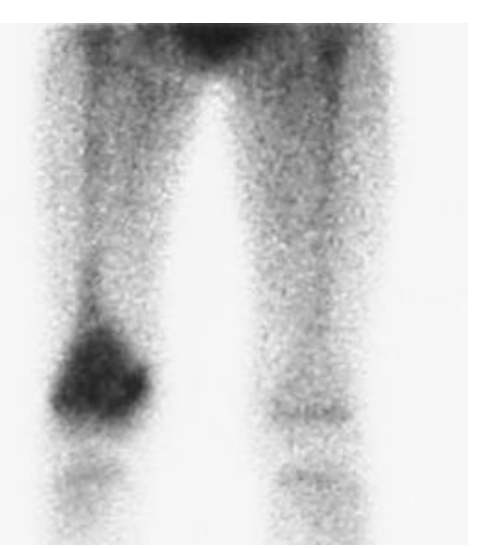

b.

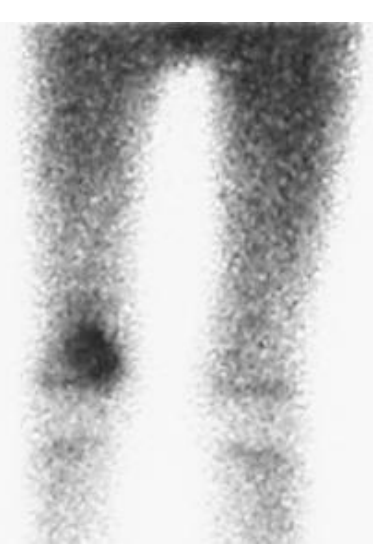


Copyright Transfer Form
This piece of the submission is being sent via mail

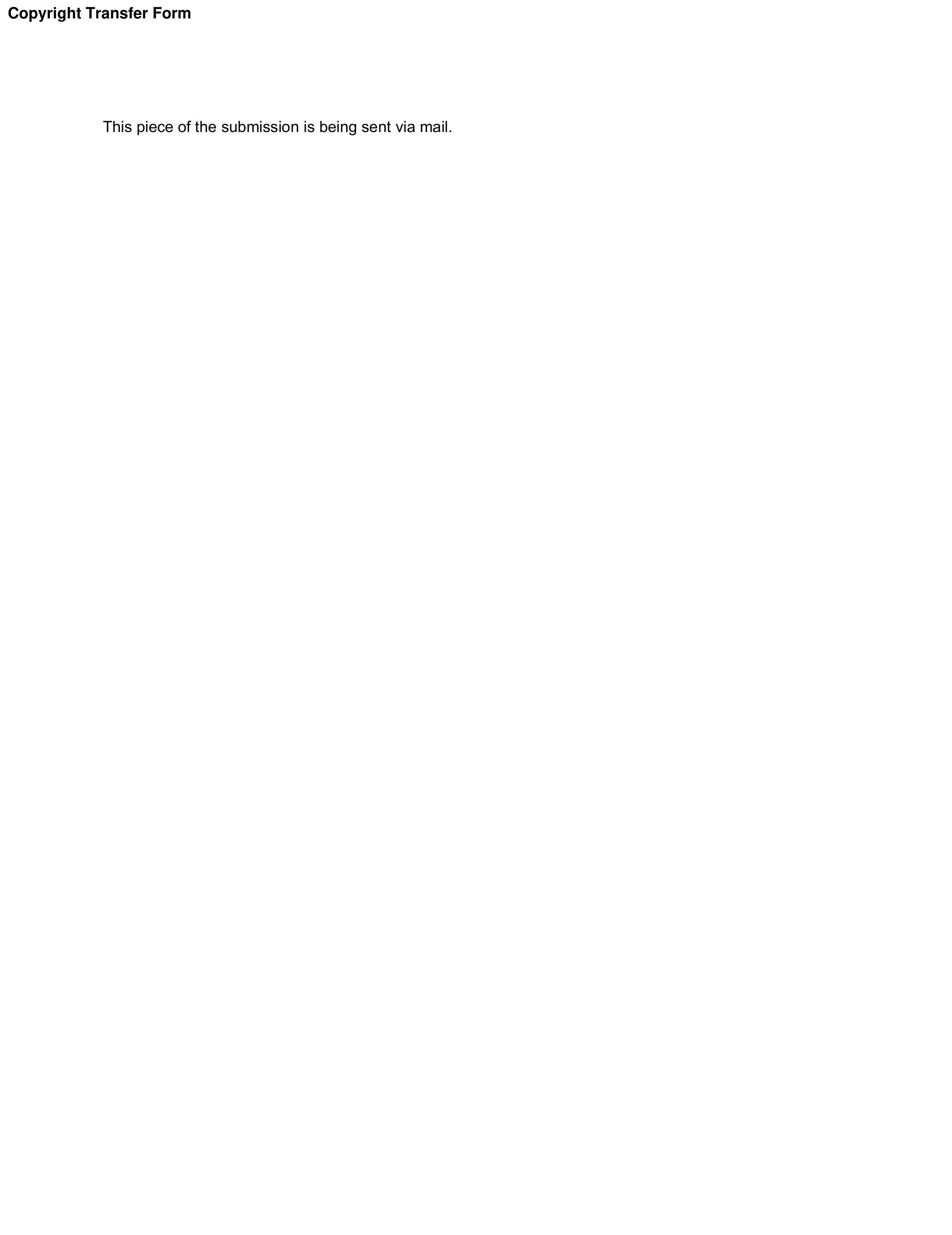

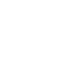

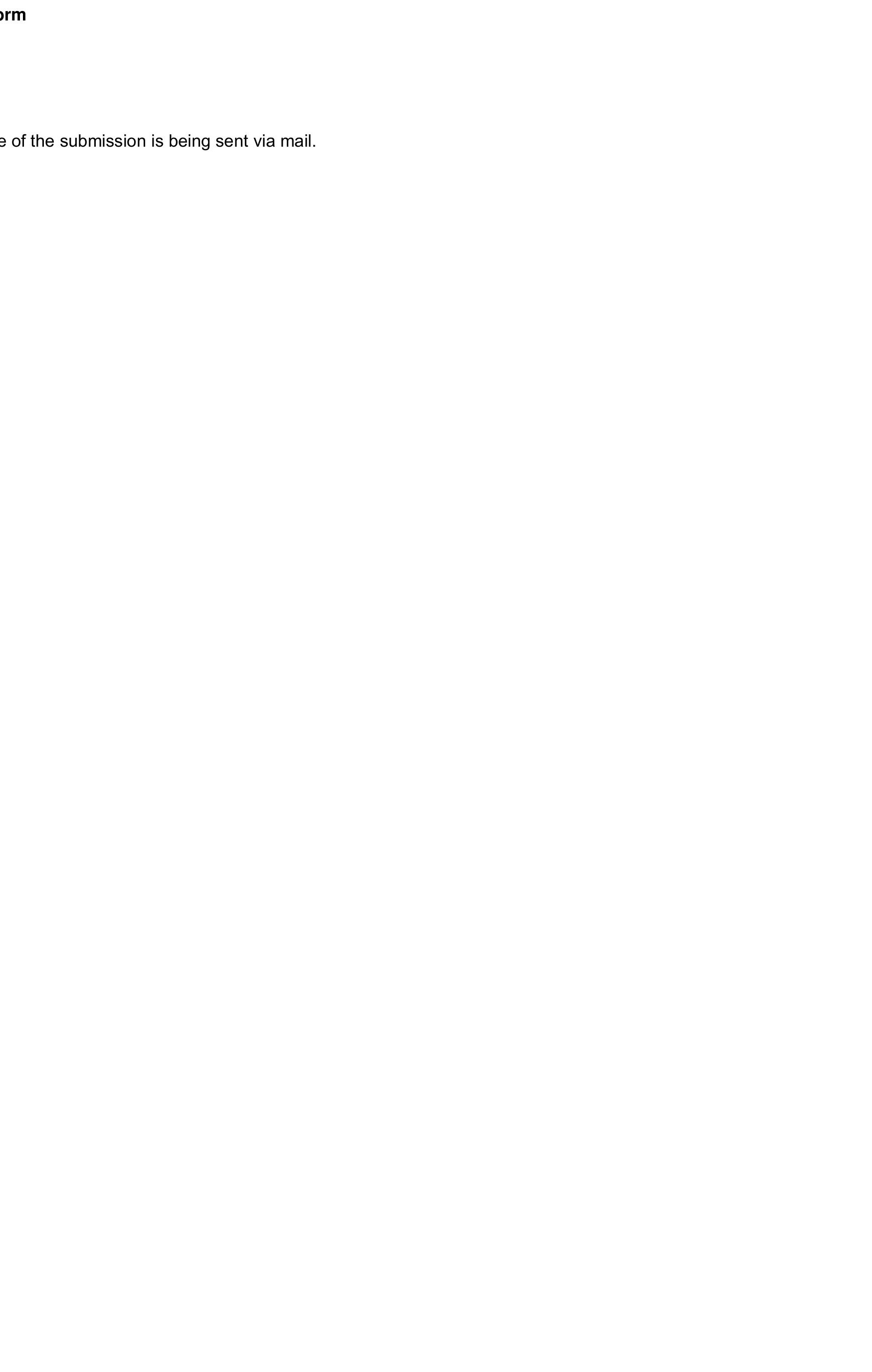

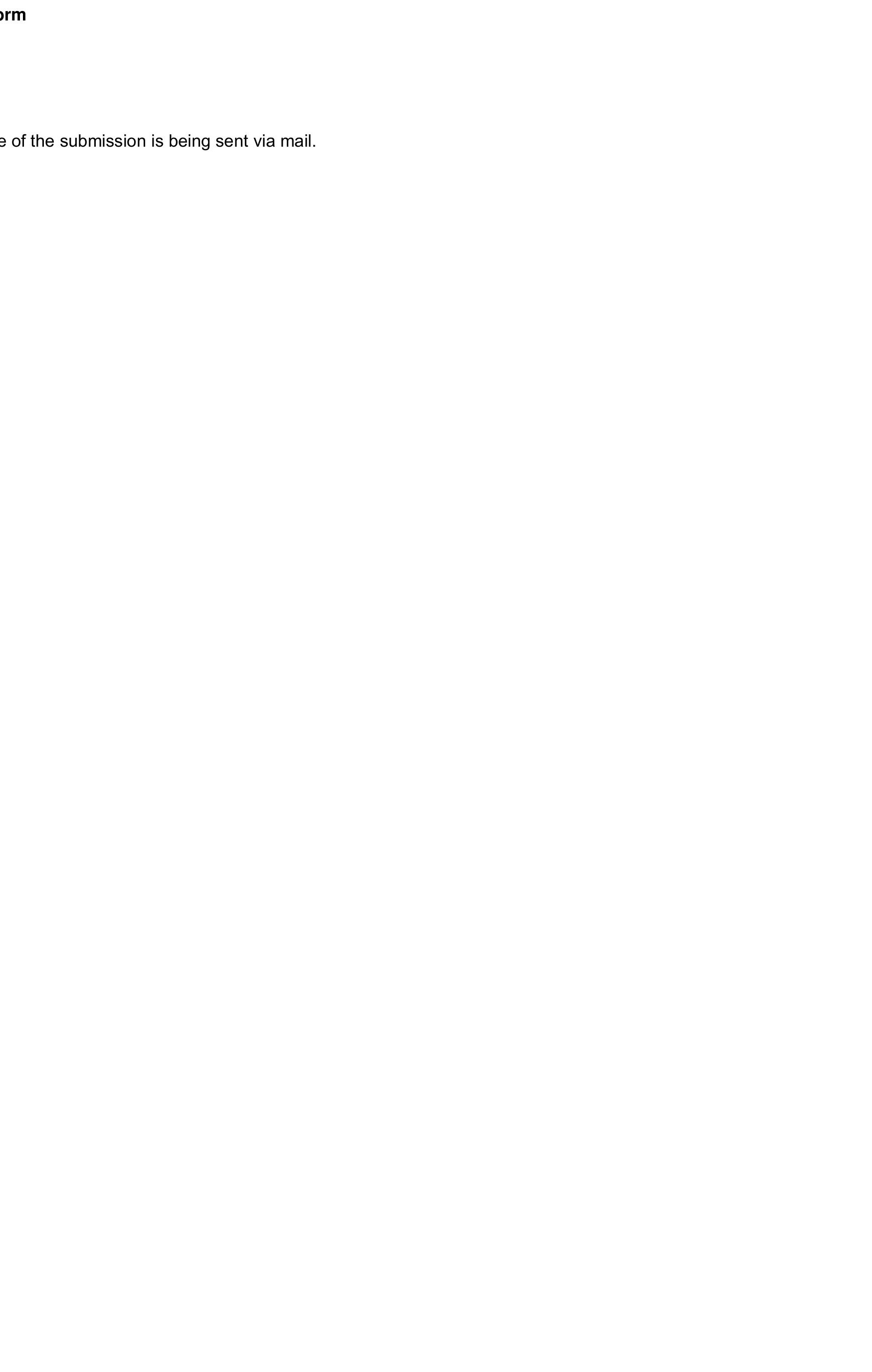

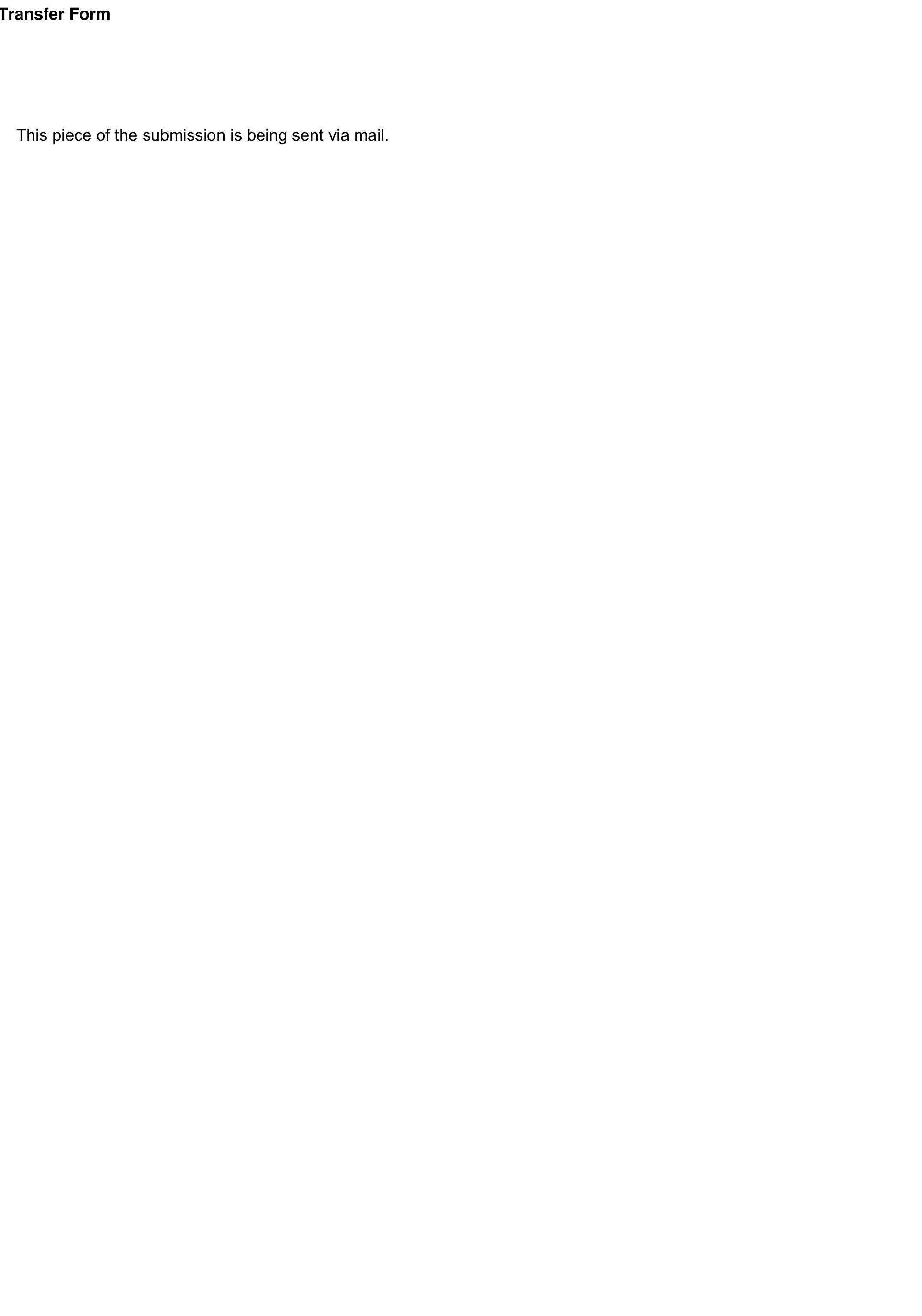

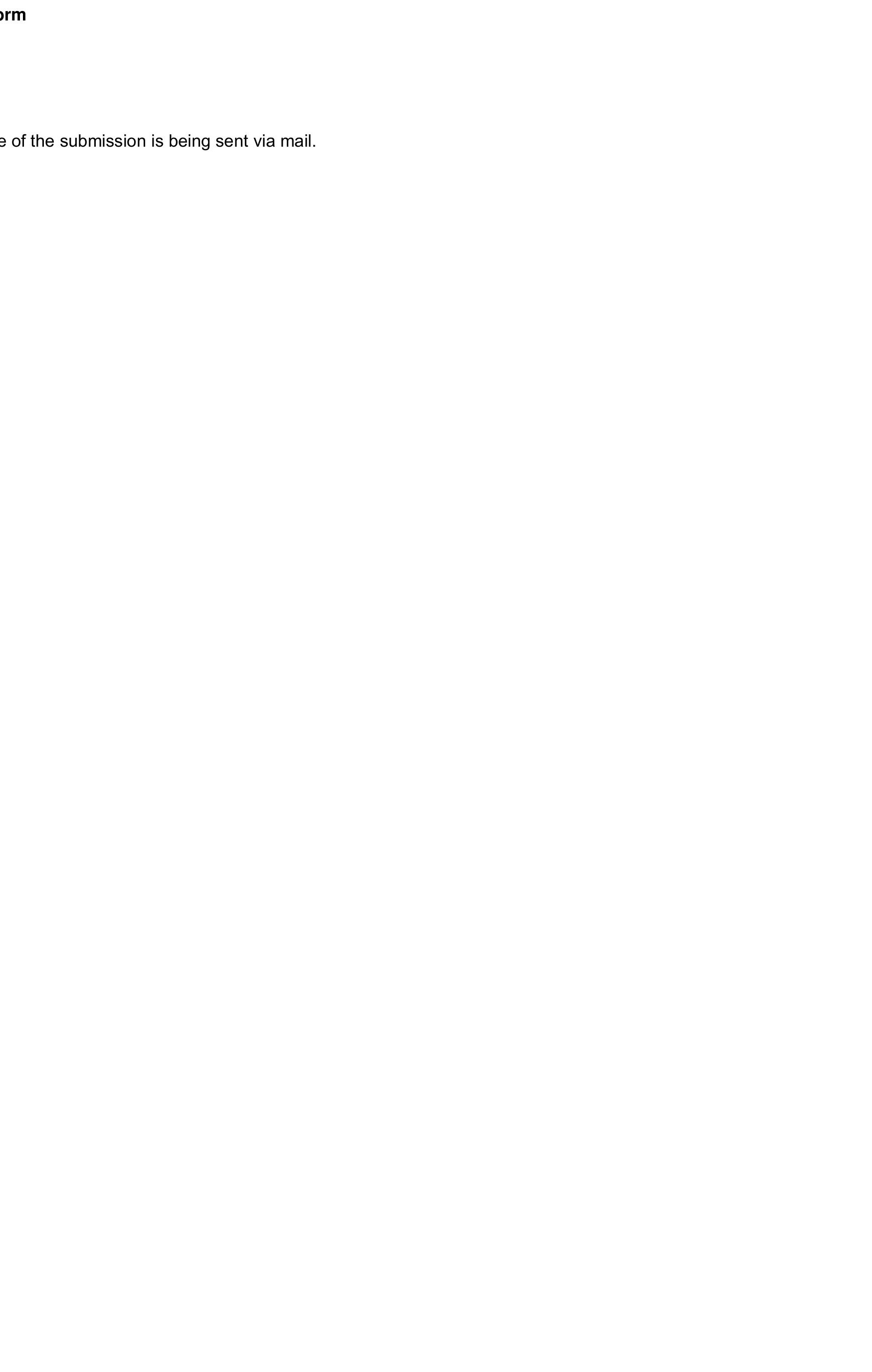

